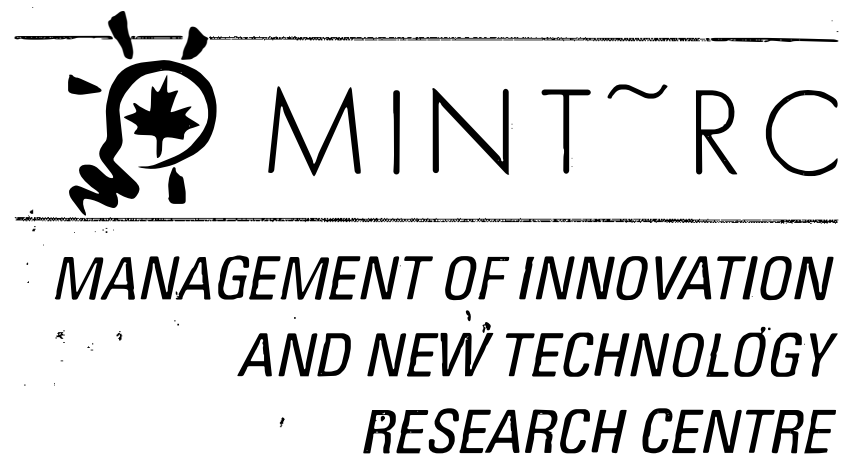

THE ECONOMIC, SOCIAL AND PSYCHOLOGICAL OUTCOMES OF IMPLEMENTING A DELIBERATE PROCESS OF ORGANIZATIONAL CREATIVITY

by

Min Basadur

Management of Innovation and New Technology

Research Centre

WORKING PAPER NO. 100

December, 2000

Innis

HD

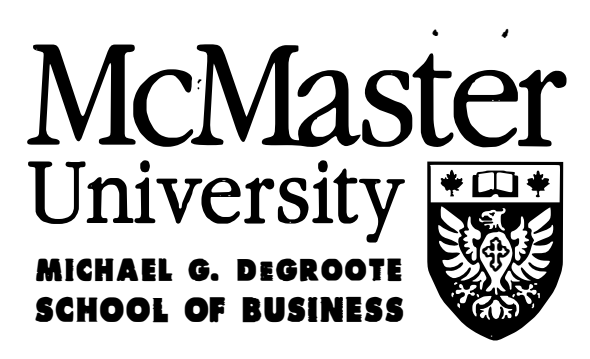

45

.W657

no.100 


\title{
THE ECONOMIC, SOCIAL AND PSYCHOLOGICAL OUTCOMES OF IMPLEMENTING A DELIBERATE PROCESS OF ORGANIZATIONAL CREATIVITY
}

\author{
by \\ Min Basadur \\ Management of Innovation and New Technology \\ Research Centre
}

WORKING PAPER NO. 100

December, 2000

The Working Paper series is intended as a means whereby a researcher may communicate his or her thoughts and findings to interested readers for their comments. The paper should be considered preliminary in nature and may require substantial revision. Accordingly, this Working Paper should not be quoted nor the data referred to without the written consent of the author. Your comments and suggestions are welcome and should be directed to the author. 
THE ECONOMIC, SOCIAL AND PSYCHOLOGICAL

OUTCOMES OF IMPLEMENTING A

DELIBERATE PROCESS OF ORGANIZATIONAL CREATIVITY

by

Min Basadur

Michael G. DeGroote School of Business

McMaster University

December 2000 


\section{THE ECONOMIC, SOCIAL AND PSYCHOLOGICAL OUTCOMES OF IMPLEMENTING A DELIBERATE PROCESS OF ORGANIZATIONAL CREATIVITY}

In an era of rapidly accelerating 'change, thriving organizations are not merely efficient but adaptable, that is, innovative. They act as open systems, that is, they are sensitive to their environment and transform continuously changing inputs into continuously changing outputs. Organizational innovation is modeled as a continuous, creative process of deliberately generating and formulating new problems and opportunities and creating and implementing new solutions. Success in this four stage process depends on four creative thinking skills: active diverging, active converging, and horizontal and vertical deferral of judgment. By deliberately encouraging people to develop skills in applying such a creative process to their work daily, an organization can simultaneously achieve both the economic outputs they crave and also the people outputs they must provide to assure motivation and continued economic success in the long run. The continuous creative process is integrated into an open systems model that features both economic and people inputs and outputs and also features two environments - internal and external through which the people and economic inputs/outputs must filter. 


\section{THE ECONOMIC, SOCIAL AND PSYCHOLOGICAL OUTCOMES OF IMPLEMENTING A DELIBERATE PROCESS OF ORGANIZATIONAL CREATIVITY}

\section{INTRODUCTION}

Most individuals spend much of their lives working in some form of organization. They are dependent on organizations for their livelihood as well as for satisfaction of many of their psychological needs. How well an organization can meet individual needs is heavily dependent on its ability to prosper in its environment. The organization is dependent on its members for motivation to apply skills, knowledge, and creativity to their work. Individuals who work in organizations that cannot prosper, will not long be able to achieve their personal goals through the organization.

Beer (1980) suggested that the well-being of society is dependent on effective relationships between (1) individuals and their organization, and (2) between organizations and their external environments. If the first relationship is ineffective, the psychological well-being of the employees is in danger. Labor strife, job dissatisfaction (at all levels), turnover, and absenteeism are continued reminders that this relationship is a difficult one to manage. If the second relationship is ineffective, economic viability in global markets becomes a concern not only for organizations but also for whole societies world-wide. Fortunately, these two relationships are not mutually exclusive. The purpose of this chapter is to show how a process of innovative thinking and decision-making can be deliberately encouraged and applied as an organizational force to achieve important motivational, people-centered outcomes and important economic outcomes simultaneously, without sacrificing one for the other. 


\section{Open System Organizations}

An organization can be visualized as a transformational engine comprising people, equipment, and processes which continuously converts changing inputs from the external environment into changing outputs to the external environment. The extent to which organizations pay heed to their external environments is said to be a measure of how "open" or "closed" they are. The external environment includes things like customers, the ecology, the govermment, competitors, suppliers, technology and society as a whole. Closed-system organizations ignore environmental changes while open system organizations continuously transform environmental changes into improvements in effectiveness. A closed system survives only if the external environment remains stable, allowing the organization to continue to take in the same unchanging inputs and emit the same outputs endlessly.

Therefore, one requirement for an effective organization is to achieve an effective relationship with its external environment. However, another requirement is to achieve an effective relationship with its internal environment. An organization's internal environment can be considered to have three main components which shape the behavior of its employees. The three are its structures, its culture and its dominant coalition (Beer, 1980). Structures are the formal aspects of an organization which signal to people that certain behaviors are desirable and that rewards are likely to result if they practice them. Structures include training; organization design and job design; personnel policies and systems with regard to rewards, compensation, promotion, labor relations, performance evaluation, recruitment, selection, and transfer; and control systems covering management information, accounting, and budgeting.

Culture relates to an organization much as personality or self-concept relates to an individual. As individuals in organizations work with others, are trained and supervised, and are affected by policies and procedures, they develop a composite perception of their internal 
environment, expressed by such concepts as "open", "risk taking", "warm", “tough", "soft", “impersonal", "informal", and "rigid". Margulies and Raia (1978) defined the culture of the organization as the shared beliefs and feelings which form an informal set of ground rules about what is expected and what will be rewarded (formally or socially).

The dominant coalition is a group of key decision makers whose influence on the system is greatest (Kotter, 1978; Miles \& Snow, 1978). It usually includes senior management but can also include others less obvious on the organization chart. Their collective job experiences, skills, cognitive orientations, personalities and values predispose these decision makers to define the internal environment in a way that is consistent with who they are as individuals and their own self-concepts. Similarly, they are likely to reinforce peoples' behaviors consistent with their own self-concepts and values.

An open systems model that includes the effects of the internal and external environments on the transforming engine is shown in Figure 1. It recognizes that the organization is both an economic and social system with multiple purposes and outcomes, and that the people and economic inputs and outputs must filter through both environments. Financial indicators such as profit and retum on investment (R.O.I.) are typical economic criteria of organizational performance. People criteria are often summarized as quality of work life (Q.W.L.) and include things like job satisfaction, equitable pay, meaningful work, and a compatible social environment. Beer (1980) suggested that the organization must provide for a satisfactory quality of work life or it will ultimately be unable to attract, keep, motivate, and influence employees and that these two sets of criteria create conflicting demands. Managers often feel forced to tradeoff one objective against another such as reducing profits to pay people more or declaring a dividend while laying off people to reduce costs. Managers tend to weigh 
the impact of decisions on both sets of outcomes and try to balance them, usually sacrificing one for the other.

Figure 1

An Organization Operating as an Open Economic and Social System

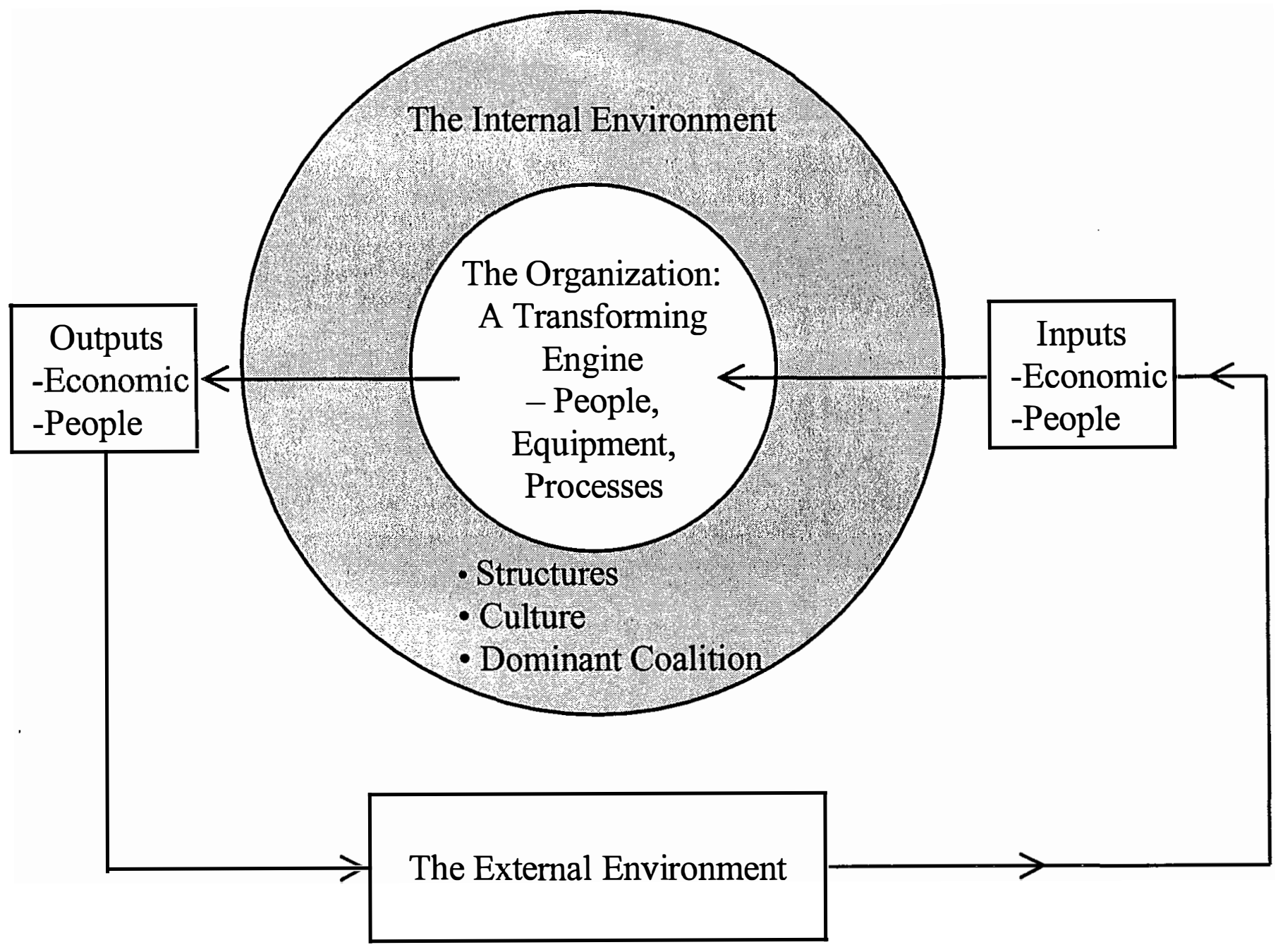




\section{Organizational Effectiveness, Adaptability and Creativity}

The purpose of this chapter is to demonstrate how these two outcomes can be accomplished simultaneously without trading one for the other. The secret is to use the internal environment to deliberately encourage employees to participate in organizational creativity and apply a user friendly, simple process of innovative thinking to their jobs. By providing a common thinking and problem solving language, this process helps harness everyone's own unique approach to creativity. How and why this process of creativity works to realize the economic and people outcomes concurrently is best understood by first understanding the relationship between organizational effectiveness and organizational creativity and, second, understanding the impact of participation in creative work on people outcomes.

Mott (1972) showed that effective organizations have two very different major characteristics: efficiency and adaptability. Efficiency means optimizing, stabilizing and polishing current methods (routines) to achieve the highest quantity and quality at the lowest cost possible. Adaptability means deliberately changing current methods to attain new levels of quantity, quality and cost and new products, and is virtually synonymous with continuous creative and innovative thinking. In the past, organizations could be effective by concentrating only on efficiency. Adaptability is now equally important because of today's rapidly accelerating rate of change (Toffler, 1970). Adaptability, that is, creativity and innovation, is needed when the organization is unclear about what needs to be done, or when what needs to be done is constantly changing. A closed-system organization works diligently to master the routine, and focuses on internal efficiency. An open-system organization works diligently to deliberately change the routine to suit its environment, and focuses on both internal efficiency and external adaptability.

Three things make it difficult for organizations to increase their adaptability performance: outdated and inappropriate organizational structures; deficiencies in commitment; and 
inadequate thinking skills. Beer (1980) suggests that the twentieth century "bureaucratic" organizations, bom out of the Industrial Revolution, are typically hierarchical in nature. They have centralized decision-making, achieve co-ordination through tight rules and controls, divide work by functional specialization, and emphasize standardization and control. Faced with changes in markets, technology, information and values, this bureaucratic organization is now under severe stress; as predicted a quarter century ago by Toffler (1970).

Employees' primary concems have expanded beyond job security and survival to include freedom, self-esteem, personal growth, and self-realization (Herzberg, 1966; Maslow, 1954). The traditional mechanism of bureaucratic organizations for attracting, motivating, and holding workers - the "economic contract" - has eroded. People have become increasingly more restive and dissatisfied with conventionally designed jobs, and less willing to obey orders without question. Young workers - particularly members of so-called Generation X who generally embrace change as the only constant in their lives - will expect more participative management and will migrate toward organizations with people-oriented work settings (Coupland, 1992).

Everywhere we look, traditional structures are being reshaped or are failing. People, and even whole communities, are finding the world moving beneath their feet as traditional markets, industries, and sources of employment disappear under the impact of new information technologies and a restructuring of the world economy (Morgan, 1993). It is not surprising that an organization whose main virtues were predictability and reliability and which operated as a closed system, should find it difficult to adapt to an increasingly dynamic environment. Many employees, too, are struggling to deal with these changes.

This chapter addresses the kind of creative, innovative thinking required to enable organizations to succeed in a turbulent world. Innovative thinking must be mainstreamed, that is, made a way of organizational life, not a "sometimes thing". Creativity is a foundation for a 
better balance of efficiency and adaptability. Optimizing the day-to-day routine often works against efforts to become adaptability-minded - to find new opportunities, to find new problems (called opportunistic surveillance by Simon, 1977), to develop new routines and products, to solve old problems in new ways, and to boldly seize, unanticipated occurrences, emergencies and crises as opportunities for innovation. Such, skill in thinking is not mainstreamed in many organizations. Many individuals display excellent analytical thinking skills but demonstrate inadequate innovative thinking skills. For example, they tend to make good short-term analytical decisions, like determining how many jobs a new piece of equipment can eliminate. The hard, innovative part is capitalizing on the opportunity by convincing head office not to lay people off but to reassign them into other important positions to build future business and improve operations, quality, and customer satisfaction. People often miss such innovative opportunities because they apply non-creative, analytical thinking routines to all situations. When situations require more than mere mathematical calculations, poor decisions or indecisiveness result.

\section{Having The Knowledge But Not Knowing How To Use It}

Many organizations have installed expensive computer systems to ensure work-related information is readily and widely available to employees. However, merely having the information is not sufficient for innovative thinking by employees. Knowing how to use the information appropriately is also necessary. A major North American Airline recently ran into a situation where all of its employees had all the lmowledge they needed but no one seemed to know how to use it innovatively. A snow storm paralyzed the home base airport on a Friday night. The snow had been expected all week, arrived on schedule, and continued through Monday. All but ten of the airline's two hundred scheduled flights were progressively cancelled as the weekend dragged on. Almost 20,000 increasingly angry customers spent a frustrating 
weekend in a survival mode. All of the airline's hundreds of ground employees knew everything there was to know about the planes, the de-icing plans, the weather and the cancellations. None seemed to know what to do, how to turm this crisis into an opportunity, how to seize the moment and make their customers feel cared for and important.

Indeed, thęir actions indicated that they believed the important challenges were getting the snow cleared and trying to fly more planes in spite of the weather. In fact, the important challenges were thinking of ways keep customers feeling well-cared for, providing customers with nourishment and sleeping arrangements, keeping the channels of communication open and friendly, and keeping spirits up. However, no one at the airline took such creative action or thought up such innovative challenges. Nobody knew a common procedure for turning a crisis into an opportunity.

In this example, all the knowledge that was needed was available but a lack of innovative thinking skill on the part of the entire airline, top to bottom, made the knowledge useless. Thinking up innovative challenges and seeing the big picture is one of the most important parts of the innovative thinking process, a learnable process which converts mere information into creative action. There is such a learnable creative thinking and problem solving process.

\section{THE THREE PHASES OF THE CREATIVE PROCESS}

People in successful, adaptable organizations think creatively and make valuable changes deliberately. They use a three-phase, creative decision making process that enables them to continuously anticipate and find new problems (new inputs), develop new solutions and implement those solutions (new outputs) (Basadur, Graen \& Green, 1982). Creativity in organizations can be defined as an ongoing cyclical process of problem finding, problem solving and solution implementation (Basadur, 1992). Problem finding means continuously finding new 
"problems" to address. Problems can be current or future internal or external changes, trends, challenges and opportunities for improvement and innovation, as well as things that are going wrong. Problem finding includes identifying new product or service opportunities by anticipating new customer needs. It includes discovering opportunities for improving existing products, services, procedures and processes, and for improving the satisfaction and well-being of the organizational members. It also means redefining seemingly insoluble problems in new ways. Problem-solving means developing new and useful solutions to problems found. Solution implementation means making new solutions succeed. Implementation usually leads to more new problem finding activity, hence the cyclical nature of the process. Thus, creativity in organizations is a process of continuous improvement, discovery and deliberate change - a continuous finding and solving of problems and implementation of new solutions - and tuming unexpected crises into opportunities.

\section{THE EIGHT-STEPS OF THE CREATIVE PROCESS}

\section{AND THE FOUR CRITICAL THINKING SKILLS THAT MAKE IT WORK}

This cyclical process in tum consists of eight steps as follows: 1) problem finding (anticipating future problems and seeking out current problems); 2) fact finding; 3) problem defining; 4) generating potential solutions; 5) evaluating potential solutions; 6) action planning; 7) gaining acceptance; and 8) taking action. The entire process, called Simplex (Basadur, 1981), is circular and continuous: each action taken to implement a new solution automatically leads to new problems, changes and opportunities for a new round of creativity. Basadur (1995a; 1997) described how Simplex field research, practical experience and theory evolved from the basic Osbom-Parnes 5-step linear Creative Problem Solving Process (Parnes, Noller \& Biondi, 1977). 
Within each of the eight steps of the dynamic, circular creative process, individuals and organizations must apply specific attitudinal and thinking skills called "process skills". Active divergence, active convergence and deferral of judgment are process skills used within each of the eight steps of the creative process. A fourth process skill, called vertical deferral of judgment, is applied between the steps of the process. Figure 2 shows the four process skills which are further described next.

Figure 2

The Four Critical Creative Process Skills

- Active divergence

- Active convergence

- Deferral of judgment

- Vertical deferral of judgment

\section{A. Active divergence}

Active divergence enables individuals and groups to generate options without judging or analyzing them. Using this process skill, they continually seek new opportunities for change and improvement; view ambiguous situations as desirable; seek potential relationships beyond the known facts; show awareness of gaps in experience; recognize the importance of discovering the right questions before seeking the right answers; and seek additional, potential solutions to problems and seek additional factors to evaluate solutions and to create successful plans for implementation and for gaining acceptance. 
An important aspect of active divergence is the concept of extended effort, which means striving to generate as many options as possible and avoiding the tendency to stop with the early options that first come to mind (Osbom, 1963; Gordon, 1956). Parnes and Meadow (1959) and Parnes (1961) conducted laboratory experiments which showed that extending effort provides significantly more good ideas in a given time period. Basadur and Thompson (1986) did field research which confirmed the usefulness of extended effort on real world managerial and technical problems for individuals and groups.

\section{B. Active convergence}

Within each step, active convergence then allows individuals or groups to select options to take to the next step. Using this process skill, they take reasonable risks to proceed on less-than-perfect options and drive each step and the process as a whole through to completion.

\section{Deferral of judgment}

Within each step, deferral of judgment separates divergent thinking and convergent thinking. By enabling individuals and groups to resist the tendency to prematurely evaluate and select options, this skill encourages active divergence. Skill in deferring judgment manifests itself in an open-minded attitude to new opportunities and facts; and a willingness to find altemative ways to define a problem, and to try unusual approaches to solve the problem and to implement the solution. 


\section{Vertical deferral of judgment}

A fourth process skill, called vertical deferral of judgment, allows the individual or group to proceed systematically through the eight steps or the three phases of the creative process, instead of leapfrogging among phases or becoming bogged down in a particular step. Vertical deferral of judgment helps individuals resist the tendency to leap directly to their preferred phase or step of the creative process. This process skill enables them to understand the difference between a "fuzzy" situation and a well-defined problem; distinguish between defining and solving a problem; unearth pertinent facts before defining a problem; recognize that imperfect solutions are merely the starting point for another round of the creative process; recognize that team members prefer different parts of the creative process; and avoid leaping to action upon discovering a problem.

Basadur, Graen and Green (1982) showed that these process skills can be leamed and deliberately developed. They identified a two-step mini-process called "ideation-evaluation" in which active divergence (ideation) and active convergence (evaluation) occur sequentially, separated by deferral of judgment. The two-step ideation-evaluation mini-process must be executed skillfully within each step of the Simplex process, and from step to step throughout the process. Figure 3 displays the eight steps within the Simplex complete creative process, beginning with problem finding and flowing through with action, with diverging and converging thinking skills in each step. In Figure 3, the two-step mini-process is represented by the "diamond" shape in each of the eight steps as the process flows clockwise. Mastering these skills enables individuals or groups to adapt the application of the process and to use the steps in different sequences as situations require. The dashed lines separating the steps attempt to indicate this flexibility. Synchronizing these skills is especially vital for group members 
attempting to work creatively together. They need to know which step of the process they are in and whether they (the team as a whole or individual members) are diverging or converging at any point in time in their deliberations.

\section{Figure 3}

How the Three Phases Correspond to the Eight Steps of the Simplex Creative Process

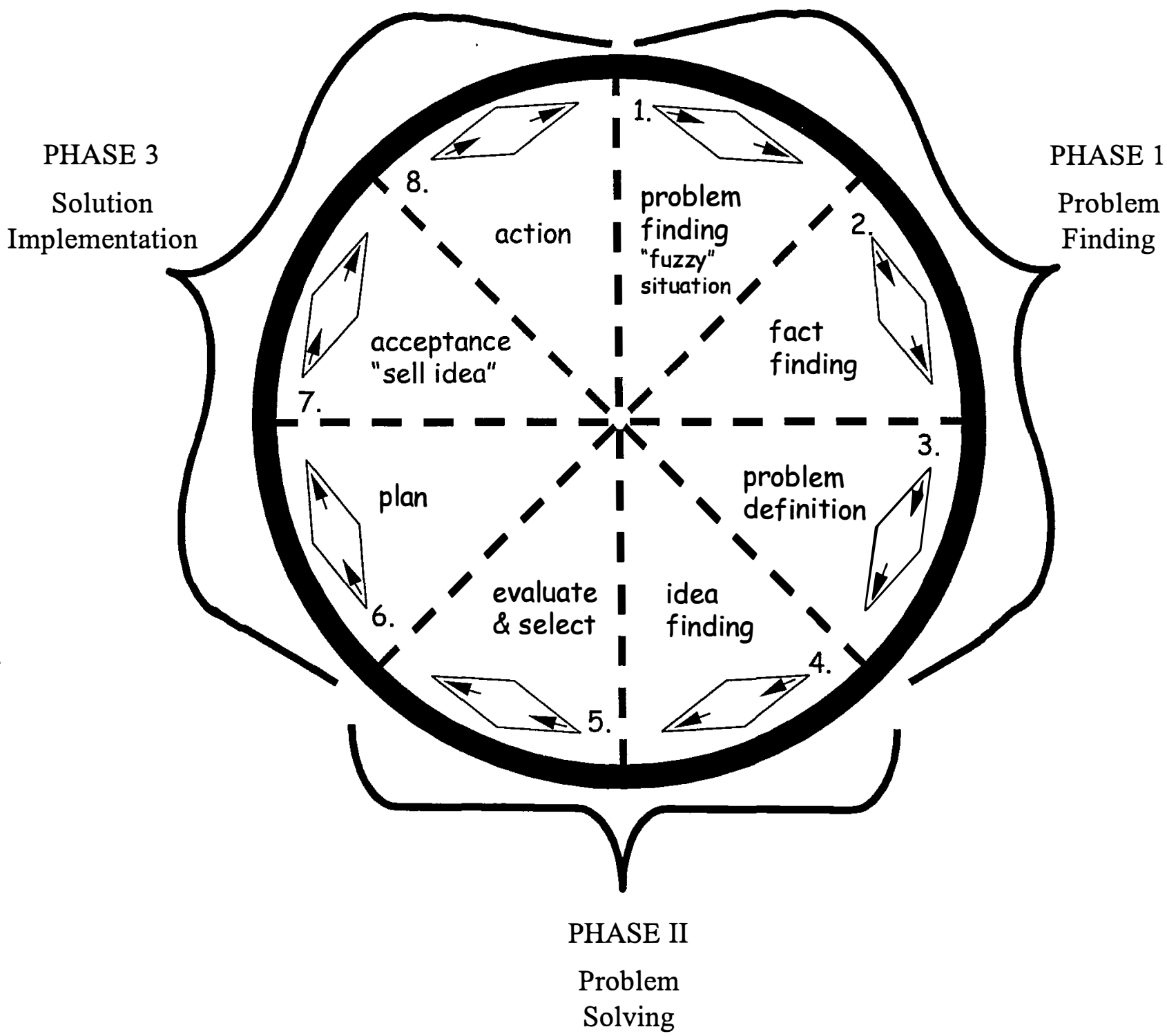


Basadur and Finkbeiner (1985) identified specific attitudes that enhance these four process skills and suggested that, unless the two-step ideation-evaluation mini-process is accepted attitudinally, then the process will not likely occur. Thus, the process skills have both attitudinal and behavioral components. Basadur and Finkbeiner established a 14-item questionnaire to measure two specific attitudes that make up the acceptance of ideationevaluation: the preference for ideation (active divergence) and the tendency to (not) evaluate prematurely (preference for deferral of judgment). They suggested that these two attitudes enhance and encourage the practice of the two related behavioral skills.

Basadur, Graen and Green (1982) and Basadur $(1979,1994 b)$ reported research that indicated that one's preference for and skill in applying the ideation-evaluation mini-process might differ in each of the three phases of the Simplex process. For example, someone might be more inclined to defer judgment and actively diverge more in the solution-finding phase than in the problem-finding phase, or vice versa. Basadur (1995b) provided evidence that there might be different optimal ratios of active divergence and active convergence in each of the phases for different fields of endeavor.

\section{Skills, Behaviors And Attitudes Are Needed to Make The Process Work}

Basadur, Graen and Green (1982) tested the effects of the Simplex process in an applied setting. They expected that the training would improve five variables: (1) acceptance of the ideation-evaluation thinking mini-process; (2) deliberate practice of the ideation-evaluation thinking mini-process; (3) problem-finding performance; (4) problem-solving performance; and (5) solution implementation performance. Basadur et al suggested that the first two variables, which are attitudinal and behavioral, were necessary antecedents of the latter three performance variables. Unless a positive change in attitudes and behaviors occurred - motivating participants 
to deliberately separate and apply divergent and convergent thinking - training would not improve performance.

This belief was based on Basadur's $(1979,1994 \mathrm{~b})$ analysis of previous laboratory and field experiments, most of which had focused on testing the brainstorming technique. None of the brainstorming research had attempted to measure to what extent the subjects accepted the value of and employed any skills in ideation-evaluation. Participants said they understand brainstorming rules, but this is entirely different from using the brainstorming rules skillfully on real-world problems. Training in innovative thinking must be of sufficient quality, impact, and duration to effect real improvements in acceptance of the skill of ideation-evaluation and of the skill itself. This distinction explains several laboratory experiments in which interacting groups receiving brainstorming instructions did not perform as well as a collection of individuals receiving the same instructions but working alone (Shaw, 1971; Taylor, Berry \& Block, 1958; Bouchard, 1972; Bouchard \& Hare, 1977; Dunnette, Campbell \& Jaastad, 1963). Unskilled group members would likely not only inhibit each other from attempting to apply the brainstorming rules but also dysfunctionally interfere with one another by mixing convergent and divergent thinking. Cohen, Whitmeyer and Funk (1960) showed that skilled groups outperform unskilled groups in creative thinking.

\section{Measuring the Needed Skills, Attitudes and Behaviors}

Basadur et al (1982) also systematically measured for the first time the impact of innovative thinking training on individuals both immediately after training and after their retum to work. Their expectations are consistent with Kraut's (1976) traditional industrial/organizational psychology training model: training must go beyond understanding to change attitudes and to change behaviors in order to achieve superior results. The results of 
Basadur et al's research supported this line of thinking. Compared to a control group, the experimental training group achieved significant increases in the acceptance and practice of ideation-evaluation and significant increases in the performance variables measured.

Basadur et al extended the research to problem finding and solution implementation as well as problem solving. Their results suggested that, compared to simple brainstorming, a complete process such as Simplex was more useful and more credible for participants (Basadur, Graen, \& Scandura, 1986; Basadur, 1997). Basadur, Wakabayashi, and Graen's (1990) field experiment supported the positive impact of building skills through hands-on practice using real problems in increasing the acceptance of creativity training among managers. Runco and Basadur (1993) supported these findings, showing that practicing managers improved their real world performance in evaluating options and increased their acceptance and practice of ideationevaluation after training in Simplex. Basadur and Robinson (1993) attributed the failure of so many new management techniques (ironically labelled "flavors of the month") to the lack of real improvement in skills.

\section{HOW THE SIMPLEX PROCESS}

\section{AND ITS FOUR CRITICAL THINKING SKILLS WORK}

The following section describes the Simplex process as a whole and provides specific real world application examples experienced by the author. Indeed, the process was developed as much by such real world application experience and field research in organizations as by theory (Basadur 1974, 1979, 1981, 1982, 1983, 1992, 1995a, b). 
A. Problem finding (Phase 1)

1. Problem finding (Step 1)

Problem finding consists of sensing and anticipating problems, changes and opportunities for improvement within and outside of the organization. The result: a continuous flow of inputs, in the form of new problems to solve, changes to address and capitalize upon, and opportunities for improvement.

A skilled problem finder takes initiative, anticipates and senses problems, and welcomes change as an opportunity to improve or gain competitive advantage. Their attitude of "constructive discontent" makes problem finders desire continuous improvement and adaptation and enables them to tolerate ambiguity and to address vague, unstructured, "fuzzy" situations. Rather than merely react to problems, they seek them out. They also view unexpected crises as positive opportunities to begin innovative thinking rather than as negative roadblocks.

Within the problem-finding step, individuals and groups continuously defer convergence and actively diverge to collect a wide variety of potentially relevant problems, changes and opportunities. Only then do they converge on a selected number for further exploration. Problem finders view even those selected problems as ambiguous, fuzzy situations.

\section{Step 1 example: Trusting myself and my colleagues}

One recurring pattem in organizations is the inability to trust oneself and one's colleagues. This results in no one wanting to ask for help or to surface organizational or 
interdepartmental problems needing solving. (These are called problems that fall "between the cracks".) Some thoughts that run through employees' heads are:

- "I fear asking for help as it might be seen as incompetence."

- $\quad$ "I don't dare mention my real problem before my fellow managers. That would be displaying weakness."

- "I don't think the group's members trust one another enough to share what is really going on."

- “This isn't really my problem, so why risk bringing it up?"

This pattem of behavior was illustrated vividly when a manufacturer's top management team once asked me to demonstrate how the eight step innovative thinking process (Figure 3) works. I told them the best way to learn was to apply the process to the team's own problems and they agreed. When we began work, we started with the first step in the process - generating and surfacing problems and anticipating, seeking and sharing opportunities for improvement. To my surprise, the team members were reluctant to risk exposing themselves to negative judgments about their handling of the problem to date. They preferred to say nothing. There was obviously no process in this company for surfacing organizational problems, that is, performing step 1 of the Simplex process.

\section{Fact finding (Step 2)}

During fact finding, the individual or group first defers judgment in order to gather potentially relevant information about a selected problem, change or opportunity. They then evaluate and select the particular facts most likely to be useful in developing fruitful problem definitions during the next step of the process. While diverging within fact finding, the individual or group defers evaluation and analysis, and accepts all points of 
view or versions of the facts. Establishing what is not known is as important as learning what is known or thought to be known. Only later during convergence does the individual or group choose the most relevant and potentially worthwhile facts.

A skilled fact finder avoids unwarranted assumptions, examines a situation from a wide variety of viewpoints, listens well to other versions of the facts and accepts those versions, extends effort to dig out further information, and asks fact-finding questions in simple ways designed to increase understanding. The fact finder can then converge upon a few key facts for further development.

\section{Step 2 example: In too big a hurry (to get the facts)}

Procter \& Gamble's fledgling Industrial Division had decided to go after a developing market for automatic car wash products in the early 1970s. In our product development department, a small team of chemists and engineers was rushing to fill out our existing product line. My boss asked me to take over the car wash section to speed up our product development efforts, especially in a floundering "hot wax" project.

Fortunately for me, I could hardly spell hot wax, let alone profess to be an expert on the product. I rarely took my own car through an automatic wash; as a young engineer, I saved money by washing my car by hand. Why "fortunately"? Because I knew nothing about hot wax, I was free to display my ignorance, keep an open mind, and ask lots of questions to try to get a handle on what needed to be done and why the project had bogged down. Thus, my first question was a very simple one: "What's hot wax?"

The team explained that hot wax was a relatively new but potentially profitable idea: a liquid spray applied as an optional service at the end of an automatic car wash. Automatic 
washes dispense all their products in water-soluble form and, of course, wax doesn't dissolve in water. However, a small competing company had found a way to combine wax from the South American carnauba tree with certain solubilizing ingredients and water, yielding a stable fluid that could be sprayed onto cars. The competitor had received a patent for its product.

Our team had spent 12 months trying to come up with a combination of camauba wax, solubilizers and water sufficiently different from the competitor's to avoid violating its patent. When asked how well the competitor's product performed, team members replied that the product was a hot seller so it was obviously doing a good job. However, no tests had actually been done because the team had been in such a headlong rush to enter the market.

When we tested the competitor's product during lab simulations and in automatic car washes, we found no evidence that it adhered to car bodies. Our team had been trying for 12 months to duplicate a product that didn't work! By redefining the problem, we ended up discovering a totally different active ingredient that helped us create a totally different formula which proved a useful benefit to car surfaces. We not only avoided patent difficulties but were awarded a new patent of our own.

\section{Problem definition (Step 3)}

During problem definition, the individual or group first uses active divergence to convert the key facts selected during the preceding step into a variety of creative challenges, or problem definitions, then selects one or a few most promising problem definitions. Here, they create a direction for solving the problem. Persons skilled in problem defining create a wide variety of insightful challenges from a few key facts. They can broaden or narrow the problem. They can break down large problems into smaller components and, at the same time, can see how those parts fit into the bigger picture. They can defer 
convergence to develop new ways of formulating the problem until they find a clearly superior problem definition.

Basadur, Ellspermann and Evans (1994) said that this step requires skill in asking the right question, which will then be answered during the next step of the process. They fully described a special process called challenge mapping, in which problem definitions are first framed as challenges, using the question: "How might we...?" This is probably the single most important question in the Simplex process, as it provides a way around the numerous roadblocks that an individual or group will encounter in attempting to develop solutions to problems. Then these challenges are further developed and new challenges are created, using a special method of divergent thinking called the "whywhat's stopping" analysis. By mapping challenges to depict the interrelationships among them, this method helps the individual or group to discover breakthrough challenges. The method involves a three-step process: asking "why" or "what's stopping" of a particular challenge; phrasing the answer in a simple, complete sentence; and creating a new challenge based on the answer. Asking these two questions repeatedly ("why else?"; "what else is stopping?") further broadens or narrows the problem's scope. This challenge mapping process yields a visual hierarchy of interrelated challenges that shows both the big picture and its components, as in Figure 4.

\section{Step 3 example: Redefining the problem}

Still at Procter \& Gamble, I was asked for help by a product development team also formed at short notice to respond to a competitor's new product. Colgate's green-striped Irish Spring had been the first striped soap bar introduced to North America. With its aggressive 


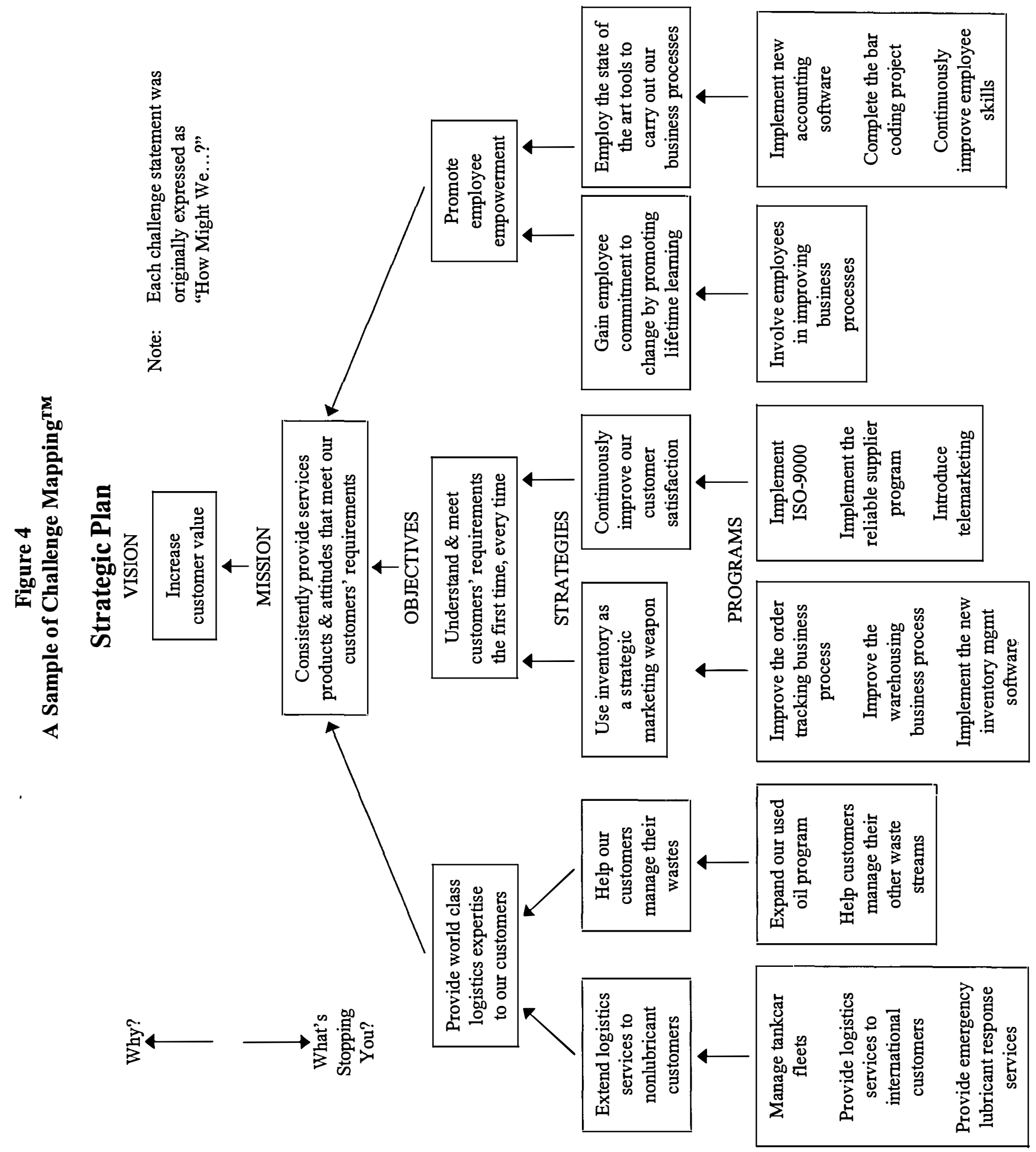


advertising campaign emphasizing "refreshment," Colgate's new product was finding ready consumer acceptance.

Procter \& Gamble: worked by the rule that, if we were the second entrant into a new market, we had to demonstrate a product's competitive advantage before we could carry out a market test. However, the team reported that it had been unable to produce a green-striped bar that worked better than Irish Spring in a consumer preference blind test. It was obvious that the team had chosen, probably unconsciously, to define its challenge as, "How might we make a green-striped bar that consumers will prefer over Irish Spring?"

During a creative problem solving meeting, we applied the "why - what's stopping?" analysis to help develop alternative ways to conceptualize our challenge. The flash of inspiration came from an answer posed from a consumer's point of view: "We want to make a bar that makes people feel more refreshed." This led us to the new challenge: "How might we better connote refreshment in a soap bar?"

This less restrictive challenge, which included no mention of green stripes, gave us more room for creative solutions. We broke this problem into three separate components - "How might we better connote refreshment in appearance, shape and odor?" - and then focused our imaginations on solutions (step 4 in the Simplex process). Beginning with the product's appearance, the team members visualized scenes, images and situations that suggested refreshment: the sea coast, a beach, looking at a blue sky and white clouds. Later, when the team sat back to evaluate its many solutions, these two ideas were selected and combined. The result was a blue- and white-swirled bar with a unique odor and shape. The product quickly achieved market success undér the brand name Coast. Solving this problem once it hả been properly defined took the team mere hours. By leaping prematurely into solutions, the team had wasted almost six months. 
Successful teams and individuals are not necessarily the "smartest" or most "gifted" or the "best" problem solvers. More often, they're the ones that take the time to ask good questions and find exciting ways to define their problem before looking for solutions. They invest sufficient time and energy in creating fresh, creative definitions of the problem on which they can agree.

B. Problem solving (Phase 2)

1. Idea finding (Step 4)

During idea finding, the individual or group practices deferral of judgment while actively creating many potential solutions to the selected challenges. They then select the most fruitful potential solutions for subsequent evaluation. Skilled idea finders use imagination to create many possible solutions - including seemingly radical or even impossible ideas that can be developed into more workable yet novel solutions. Rather than stop with the first good idea, they assume that even better ideas await. They are also skilled in selecting a few potential solutions for closer scrutiny during the next step of the process.

\section{Step 4 example: Breaking through patent barriers}

After solving the refreshment bar problem, we still weren't finished. We had to conduct another round of innovative problem solving. Before we could sell the new soap formula, we had to overcome a patent problem in the machinery design. There were already no fewer than six worldwide patents restricting how you could blend blue and white soap pastes. We had to find a machine design in order to make our product without infringing on anybody else's technique.

We assembled diverse points of view in a small technical team of engineers, technicians, lawyers and even a few people who were unfamiliar with this technology. After the team had 
spent some time in fact finding, including discussing sketches of the patented processes, a breakthrough solution soon came from a simple observation by the team member with the least technical knowledge and education. This person noted a small detail that the others had completely overlooked in their search for more complicated solutions. The lesson: it's important to value the input of each member of a team, no matter their level of experience. Sometimes the best ideas come from people unencumbered by "too much" knowledge, people who can ask the simple questions that the so-called experts overlook.

\section{Evaluate and select (Step 5)}

Evaluation and selection involves open-minded generation of many criteria that might help the individual or organization make an unbiased, accurate evaluation of the potential solutions developed in the preceding step. The individual or group then selects and applies the most significant of these criteria to decide which potential solutions might be implemented during the next stage of the process. Skillful evaluators avoid leaping to conclusions based on a single, simple criterion. They can tum flawed ideas into workable solutions.

\section{Step 5 example: Evaluating with an open mind}

A grocery products company was looking for a way to help consumers better handle their household trash. The company felt it could improve upon the polyethylene bags that most people used. A product development team was assigned to the challenge: "How might we improve the handling of household trash?"

One of several interesting and imaginative solutions that I had helped the team develop was a cardboard product that resembled a pizza box. Pushing its top made the box telescope into 
a free-standing trash container with several polyethylene bags nested inside it. This stand-alone device eliminated many of the disadvantages of single polyethylene bags. It hid the trash beneath a hinged cardboard top, and was convenient and decorative to boot. When one of the bags was filled, you simply pulled a cord to tie its top and took it out of the box, leaving the next bag ready to use. The team members appeared excited about this idea's possibilities. Before leaving the team for another assignment, I made a mental note to follow up later on its progress.

To my surprise, when I checked back with the team members, they told me they had dropped the idea. It had been evaluated through a standard company screening technique for new product ideas. Instead of designing a prototype and conducting field-tests, the consumer research department had written a single-paragraph description of the idea, including the fact that the new product would probably add about 10 cents to the cost of each bag. Asked for comments, consumers indicated the product sounded like a good idea but they would balk at paying the 10-cent premium for it. Without further consideration, the group had abandoned the idea.

I was disappointed that, after putting so much effort into generating ideas, the group had put so little emphasis on the evaluation process. Given the chance to experience the advantages rather than just read about them, consumers might have responded quite differently.

In retrospect, I felt that the team members had been almost afraid of the idea, and had been relieved to find a reason not to proceed with it. Here, creative problem solving had been used to come up with a unique product solution, only to have untested assumptions and lack of imagination kill the product before it ever got a real test. This story demonstrates the importance of keeping an open mind both in developing new ideas and in evaluating them. 
C. Solution implementation (Phase 3)

1. Action planning (Step 6)

Having developed a good solution, the individual or group then enters the implementation stage, in which they exercise skills in preparing and implementing the solution. Implementing a solution carries its attendant anxieties. In effect, people are being asked to enter the unknown, which causes discomfort because of a lack of familiarity and a fear of failure. It requires creativity to gain support for risking change, to build commitment for entering the unknown, to adapt the solution to specific circumstances, and to ensure the necessary follow-up to cement the new change. During action planning, the individual or group develops specific action steps that will lead to successful implementation of the new solution. They first generate actions, then select the specific actions.

\section{Step 6 example: Almost losing it at the last minute.}

A large marketing company's senior managers devoted a full day off-site to identify its critical strategic and tactical challenges and then figure out how to finish the fiscal year "in the black" for the first time in three years. The original pioneer in its field, the company had generated excellent sales and profits in its earlier years, but now was bogging down due to stiff competition and a lack of attention to managing its costs and operating efficiently. After considerable problem definition work, the group unanimously selected "how might we increase cash flow immediately" as their most important challenge and began generating solution ideas. After evaluation, five very simple and specific solutions were selected for implementation. These included straightforward actions such as making a list and personally calling all customers owing the company substantial sums of money and offering an incentive to pay right away. All 
that remained now was to specify a simple action plan to implement these excellent solutions in the final 90 minutes of the day.

Under the facilitator's guidance, the group quickly diverged a list of simple, specific steps it could take to begin implementing their solutions. However, when it came time to converge upon the very best and assign names and dates to them, some of the members began to lose focus and visibly back away from this task. They shifted instead into a divergent mode, creating more solution ideas and offering alternative suggestions. It was only with the greatest difficulty that the facilitator induced the whole group to focus on a workable action plan to implement the selected solutions and avoid leaving the meeting empty handed. With the plan finally in place, the team was able to immediately begin implementing the solutions, and at year end (six months later) the company reported a substantial profit.

\section{Gaining acceptance (Step 7)}

The step of gaining acceptance recognizes that the best-laid plans can be scuttled by resistance to change. The best way to reduce this resistance is to begin involving people whose commitment is needed early in the process, about step 1 or 2 . As they become part of the problem definition and the solution, the need for a separate gaining acceptance step disappears. However, this step is included in the Simplex process model to recognize its importance and to involve any individuals who were not able to be involved early in the process, for whatever reason.

Coch and French (1948) pointed out the importance of developing ownership of a new idea in order to win its acceptance. People will more likely accept change if they understand its benefits and if they see how attendant problems can be minimized. During 
this step, the individual or group generates ways to create ownership, explain the benefits and address objections. They then apply judgment to choose the best approach to gaining acceptance.

\section{Step 7 example: Getting bogged down}

Interfunctional teams formed to tackle a common problem often bog down in implementing good solutions for various reasons. Suppose a team gathers years' worth of test results to justify adopting a brilliant new method for shipping goods, but varying conditions make it difficult to obtain conclusive data. Even after it becomes obvious that the team will never amass all available critical data, it continues its investigations. The team finally realizes that its main problem is not how to collect more information, but how to face up to its fear of having to gain acceptance from top management for its recommendation with less than conclusive data.

Some thoughts running through team members' heads might include:

- "We have taken the problem as far as we can, but will senior management be happy with our results?"

- "How might we get senior management to share the risk with us?"

Good ideas often languish because people think they have to perfect their ideas before they can put forth recommendations or try winning acceptance for them. In this case, the team overcame its reluctance, and put forward a simple recommendation that summarized and weighed the benefits of moving ahead against the cost of continuing to wait for complete proof (which would never come). Top management accepted the recommendation immediately. 
3. Taking action (Step 8)

Carrying out action steps is an integral part of the creative process. At the organizational level, the result is a continuous flow of outputs in the form of products, services and processes to interact with the changing environment. Having carefully considered the specific steps in an action plan, the individual or group must still carry them out. It is at this step that individuals and teams often become mired in detail and in reasons for not taking action. Among these reasons:

- Tice and Baumeister (1997) noted that procrastination makes it difficult to take action even when the next step is obvious;

- the action plan might be too vague, complicated, difficult, distasteful or insufficiently challenging;

- fear of the unknown;

- fear of failure (and the stigma attached to failure);

- fear of implementing an insufficient or imperfect solution (compounded by a myth that answers to problems must be right or wrong);

- inability to say no to less important but easier tasks.

Lakein (1973) described techniques for overcoming hurdles to taking action, including the following:

- Start with even the most trivial step.

- Make action plans extremely simple, specific and challenging, yet realistic.

- Start with the least desirable step.

- Face fear of the unknown by writing down the worst that could happen, then creating ideas for coping.

- Address fear of failure by sharing the action plan with others and by developing strategies to minimize discomfort or even to turn failure to advantage.

- Learn to say no to distractions. 
- Set written deadlines and share those commitments with others. Promise simple but significant rewards for meeting those deadlines.

\section{Step 8 example: Wanting a new management style, but ...}

In the Step 1 example above, the manufacturer's top management team finally was able to select an important and mutually agreed upon recurring problem. With tension now reduced, the fact finding and problem definition steps went very well and an excellent solution emerged that was simple and novel, and a simple action plan emerged. But as we moved to implement this plan, some members began to back away from it because they realized that non-management employees would be participating in developing and implementing the solution. They were actually afraid of straying into unfamiliar territory and would prefer the relative safety of the team's admittedly poor but more customary approach of leaving the problem unsolved.

Some thoughts that probably were running through these managers' heads were:

- "I want employee involvement. But if I allow too much leeway for self-management and creativity, I don't know where employees will take it."

- "Deep down, we fear getting involved. We fear the unknown. We might not be ready for more innovation."

The leader of the top team understood the fears and reluctance of the members and worked behind the scenes to coach them to final implementation. Many people would rather stay with the way things have always been done rather than take the risk of trying something new. But they can break through this fear with encouragement and the support of top management, and with practice. 


\section{INDIVIDUAL STYLES IN THE CREATIVE PROCESS}

A good way to increase understanding of the eight step Simplex creative process above is to experience the Basadur Creative Problem Solving Profile (CPSP) inventory. Basadur, Graen and Wakabayashi (1990) published this instrument as a method of learning the circular eight step process and also as a method of learning one's own relative preferences for different parts of the process. They included reliability and validity data. Later, Basadur, Wakabayashi and Graen (1990), Runco and Basadur (1993), and Basadur (1995b; 1998a; 1998b) published extensive additional field reliability and validity field research on the CPSP.

\section{The Two Dimensions of the Creative Process: Different Ways of Gaining Knowledge and}

\section{Using Knowledge}

One basic idea behind the CPSP is that creativity can be understood as a function of knowledge, imagination and evaluation. Parnes, Noller and Biondi (1977) provided this idea in equation form: $\mathrm{C}=\mathrm{K} \times \mathrm{I} \times \mathrm{E}$. A second basic idea is that different individuals have different ways of gaining and using knowledge and therefore have different styles of using the creative process. As shown in Figure 5, one way of learning is by direct, concrete experiencing (doing). Some people prefer to gain understanding by such "physical processing". An opposite way of learning is through detached, abstract thinking (pondering). Some people prefer to gain understanding by such "mental processing". All individuals gain knowledge and understanding in both ways but the relative amounts of each differ from person to person.

Also as shown in Figure 5, one way of using knowledge is for creating options (ideation or active divergence). Another way to use knowledge is for evaluating options (evaluation or active convergence). Again, all individuals use their knowledge in both ways but the relative amounts of each differ from person to person. 
Figure 5

\section{Differences in Gaining and Using Knowledge that Cause Differences in Creative Process Profiles}

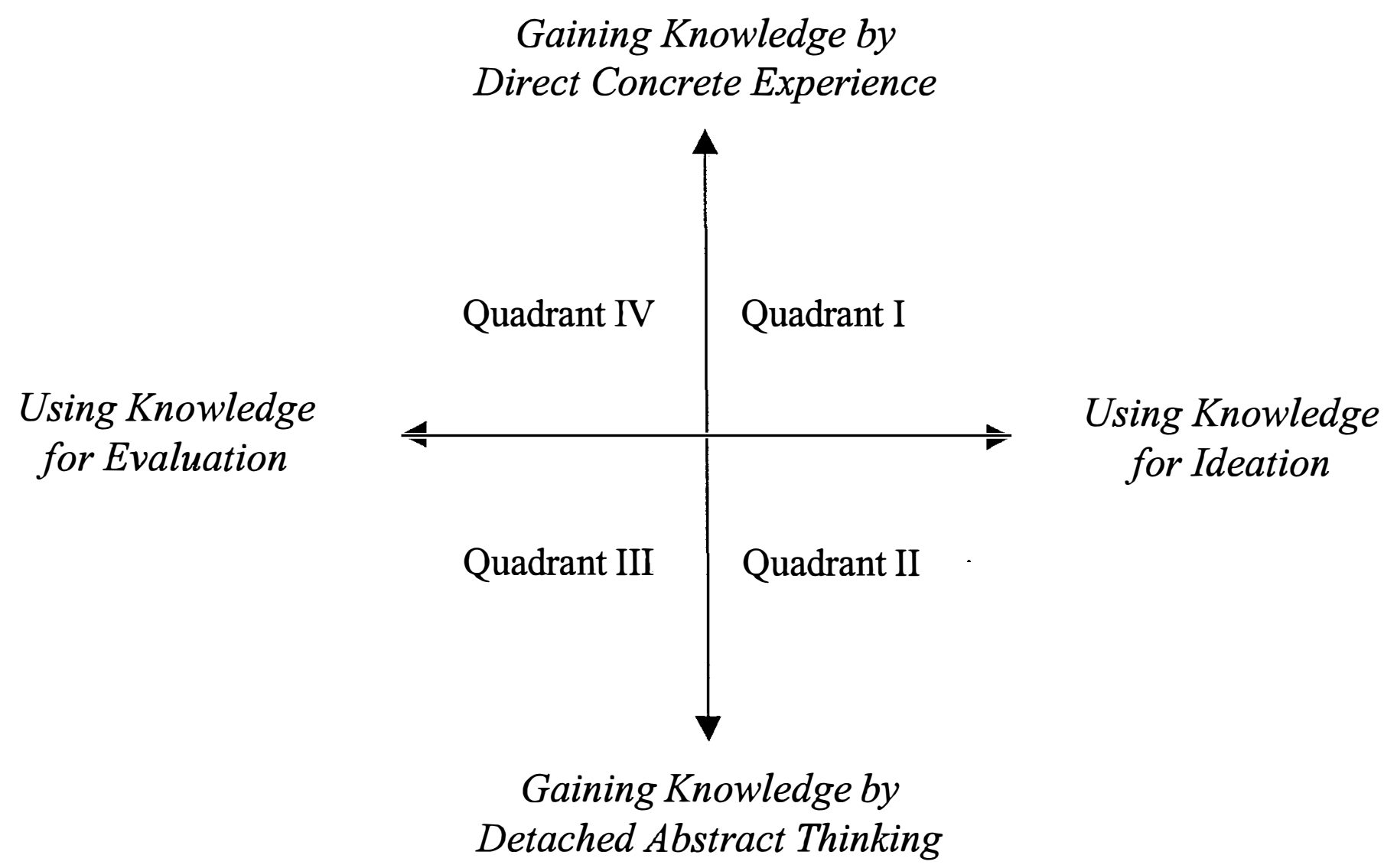

The Simplex 8-step process can be divided into four stages or quadrants. Each stage of the process reflects a unique combination of one of two different ways of gaining knowledge and one of two ways of using knowledge. The creative process requires four distinctly different thinking styles represented by these four special combinations of how knowledge is gained and used. The four stages or styles (Figure 6) are generating, conceptualizing, optimizing, and implementing. 
Figure 6

The Four Stages of the Innovative Process

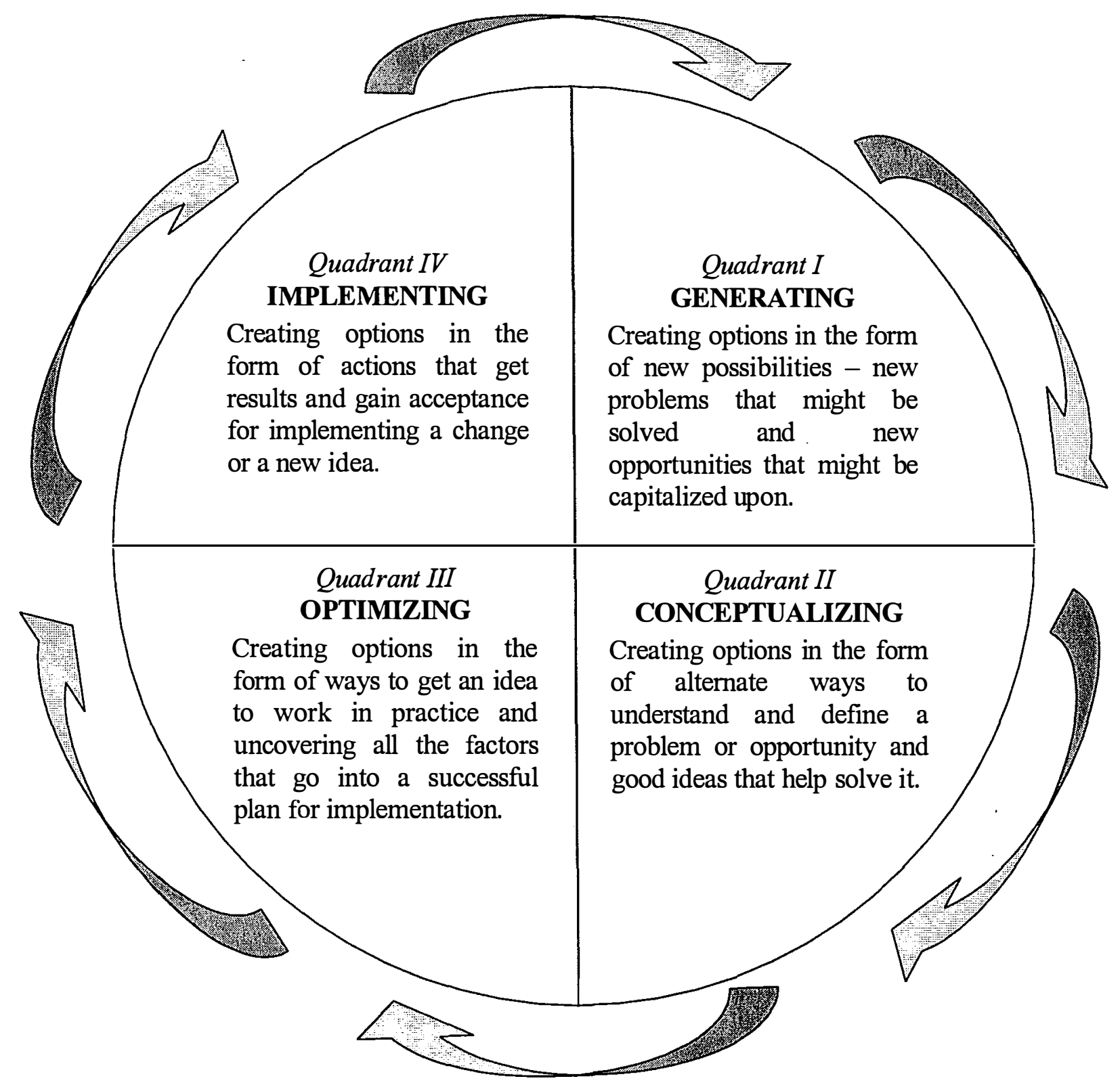


Following is a brief description of each stage or style. For a more complete description, refer to Basadur, Graen and Wakabayashi (1990) and the other references above.

\section{Four Different Creative Process Styles or Stages}

Stage 1: Generating

Generating involves creating options in the form of new possibilities - new problems that might be solved and new opportunities that might be capitalized upon. Thinking in this quadrant includes problem finding and fact finding, the first two steps in Simplex, and begins the innovative process.

\section{Stage 2: Conceptualizing}

Conceptualizing involves creating options in the form of alternate ways to understand and define a problem or opportunity and good ideas that help solve it. Thinking in this quadrant includes problem defining and idea finding, the third and fourth steps in Simplex, and keeps the innovative process moving.

\section{Stage 3: Optimizing}

Optimizing moves the innovative process further and involves creating options in the form of ways to get an idea to work in practice and uncovering all the factors that go into a successful plan for implementation. Thinking in this quadrant includes idea evaluation and selection, the fifth and sixth steps in the Simplex process, and action planning. 
Stage 4: Implementing

Implementing completes the innovative process cycle, and involves creating options in the form of actions that get results and gain acceptance for implementing a change or a new idea. Thinking in this quadrant includes gaining acceptance and implementing, the final two steps in the Simplex process.

\section{The Four Stages as a Flow}

Briefly, the innovation process as modeled in Figure 6 works as follows. Generating ideas for new products, services and methods and internal improvements must start somewhere. Individuals inclined toward generating are continually scanning the environment, picking up data and cues from customers, suppliers and others, and suggesting possible opportunities for change and improvement. Thus, the generator stage is where new information and possibilities are raised as starting points for new projects. People who tend to have dominant conceptualizer styles lead the pulling together of the facts and idea fragments from the generator phase into well-defined, insightful problems and challenges and more clearly developed ideas and projects worth further evaluation. Good conceptualizers give sound structure to fledgling ideas and opportunities. People with optimizer preferences usually lead in taking these well-defined ideas and finding a practical best solution and detailing efficient plans for proceeding. Finally, those who enjoy the implementation phase of innovation will lead in carrying forward the practical solutions and plans to implement them. This includes convincing colleagues or customers of the worth of the changes, and adapting the solutions and plans to make them fit real-life situations and conditions.

The CPSP permits an individual's unique preference approach to applying the Simplex creative process to be identified. In order to better understand these orientations and to 
determine their own preferences, individuals complete a creative problem solving process inventory then plot their scores on each of the four dimensions of the graph in Figure 7. By connecting the four points on the four axes of the graph with four curved lines, one creates one's own unique blend of the four quadrants to determine, their unique creative process profile.

\section{Creative Process Profiles}

One's creative process profile will likely be skewed toward particular quadrants to reflect the individual's peculiar blend of styles. The largest of the four quadrants indicates the strongest orientation. The others represent supporting orientations. Figure 8 shows how individual differences in orientation can yield different creative process profiles, and illustrates different profiles in which there is more than one substantial style represented. Each of these styles reflects individual ways of gaining and using knowledge.

\section{Blends of Styles in Individuals and Organizations}

All individuals, teams, and organizations can be characterized by their peculiar blends of these four distinct orientations or styles. An innovative team requires preferences and strengths in all four stages. Team members must learn to use their differing styles in complementary ways. An individual's, team's, or organization's unique blend may change over time or from one situation to another depending on circumstances. With rapid changes in markets and technologies, for example, some large corporations more recently have had to balance their traditional emphasis on optimizing and implementing with more generating and conceptualizing (Basadur, 1997). Current research on the CPSP includes investigating if optimal blends of styles may exist for teams in various kinds of innovative work. 


\section{Figure 7}

\section{CPSP Profile Graph}

LEGEND: Column 1 scores indicate the orientation to getting knowledge by Experiencing. (Direct personal involvement).

Column 2 scores indicate the orientation in using knowledge by Ideation. (The generation of ideas without judgment).

Column 3 scores indicate the orientation toward getting knowledge by Thinking. (Detached abstract theorizing).

Column 4 scores indicate the orientation toward using knowledge for Evaluation. (The application of judgment to ideas).

Post your total scores for each column on the appropriate axis below.

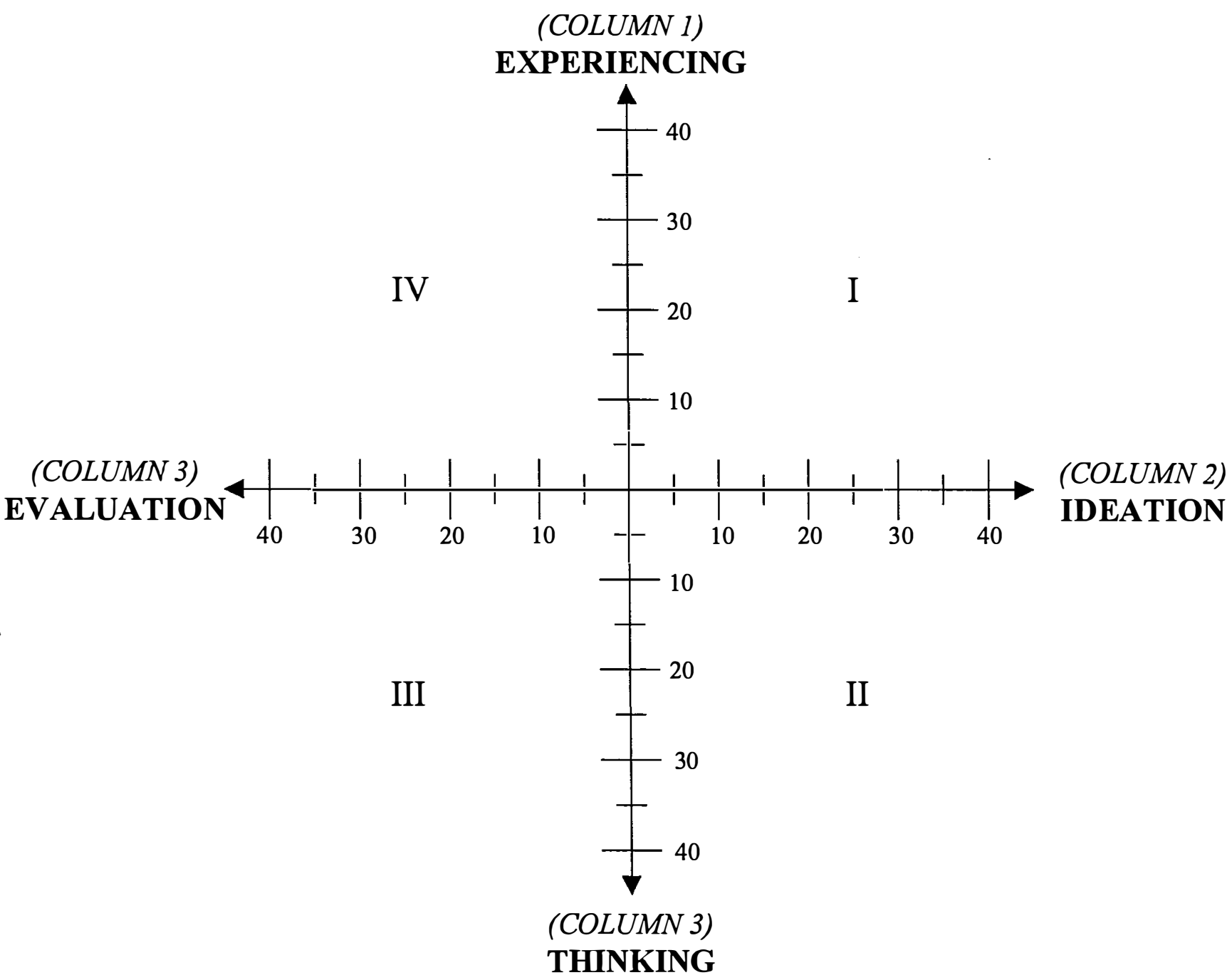

To develop your personal creative process profile, simply connect the 4 points in sequence with 4 curved lines to make a distorted or "warped circle accordingly. (If you have identical column scores, you will have a perfect circle. This is unlikely.) The quadrant in which your profile is most dominant indicates your strongest orientation. The other quadrants represent secondary styles accordingly. Your profile is your own unique blend of the four quadrants. 
Figure 8

\section{Examples of Different Profiles of Creative Problem Solving With the Same Style Dominant and With Different Styles Dominant}

\section{(All Four Examples Below Have The Generator Style Dominant)}

Generator style dominant with all three other quadrants relatively small.

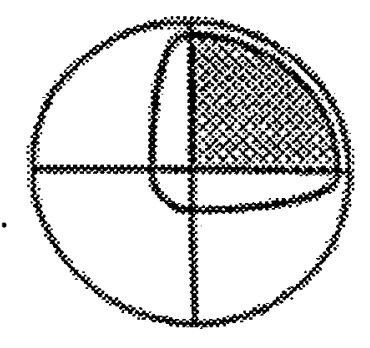

Generator style dominant with Implementer style as strong secondary.

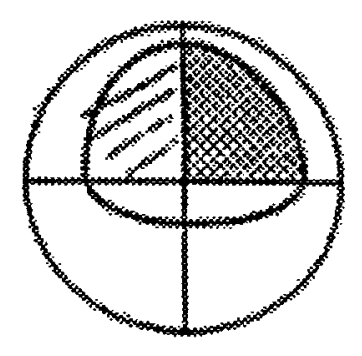

Generator style dominant with Conceptualizer style as strong secondary.

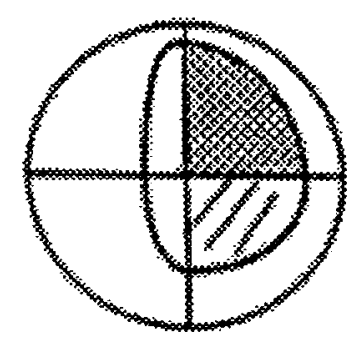

Generator style dominant with Conceptualizer and Implementer as secondary styles of significant and equal strength.
(All Four Profiles Below Have
Different Styles Dominant)

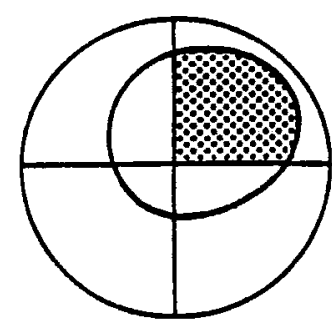

Generator style dominant with all three other styles relatively small.

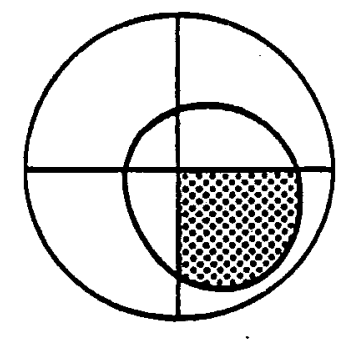

Conceptualizer style dominant with all three other styles relatively small.

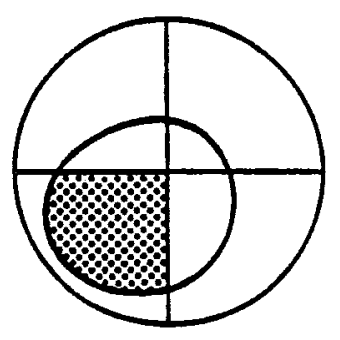

Optimizer style dominant with all three other styles relatively small.

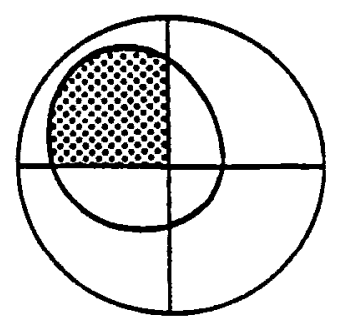

Implementer style dominant with all three other styles relatively small. 


\section{BY INCREASING CREATIVITY ORGANIZATIONS GET \\ TWO FOR THE PRICE OF ONE}

Organizations whose dominant coalitions provide the right skill training, create the right infrastructure, and participate in and reward continuous problem finding and solution implementing, achieve several outcomes. Some creativity outcomes are directly economically oriented and others are not. As described earlier in this chapter, creativity leads directly to new and improved products and methods; these are economic outcomes associated with adaptability. However, creativity also leads to specific people outcomes which serve as intermediate steps leading to economic outcomes associated with efficiency (Basadur, 1993). The rest of this chapter will identify these intermediate outcomes, and describe the economic outcomes that result. The first of these people outcomes is motivation.

\section{Creativity for Motivation}

Creativity as a means for motivation is an important idea. Early animal research and later studies on humans showed that curiosity, activity, and exploration are enjoyed by organisms for their own sake. People develop negative attitudes toward repetitive tasks and experience fatigue and boredom. This suggestion is supported by Herzberg, Mausner, and Snyderman's (1959) research suggesting that challenging jobs are motivating in themselves. Herzberg et al propose that the way to motivate most people is by redesigning and enriching their jobs so that the work itself provides the opportunity for personal growth, challenge, stimulation, leaming, and recognition. More recently, Amabile (1993) and Hackman and Oldham (1980) have reported research linking intrinsic motivation and creative work. Neher (1991) although critical of Maslow's motivation theory, supports Maslow's (1954) contention that although lower level motivations can provide important fulfillments and satisfactions, offering people the opportunity 
to satisfy their higher level needs for self-esteem and for self-actualization through work accomplishment is the best way to motivate them. Encouraging organizational members to use their creativity to seek out work related challenges of their own (problem finding) and achieve them successfully (problem solving and solution implementation) helps satisfy both higher level needs.

McClelland $(1951 ; 1961)$ identified the need for achievement as a primary driving force for motivating people in organizations. McClelland showed that a high need for achievement is characterized by a strong desire to assume personal responsibility for finding solutions to problems and can be increased by stimulating people to set challenging work goals for themselves. Thus, by giving employees the encouragement and opportunity to find and solve their own challenging problems, and implement their own solutions, organizations can provide intrinsically rewarding work and tap into the need for achievement for motivation.

Problem-finding activity is also the key to other theories of motivation. One is the goal setting theory of Locke and Latham (1990) who showed that when people are given a chance to choose their own goals (problem finding), and the more clear and specific the goals (the problem-definition aspect of problem finding), the more motivated they become to achieve those goals.

\section{Setting Up The Internal Environment To Encourage Creative Work}

Despite research showing that most people at work are multimotivated, the majority of global business and industry is still organized and managed on the overly simplistic, "scientific management" concept made popular in the early $20^{\text {th }}$ century by Frederick Taylor (1967). Taylor believed that employees are motivated by one dominant factor - money. Fortunately, using creativity as a formula for motivation can be almost as simple as using money. There are many 
straightforward ways to encourage people to be creative on the job and achieve a motivated organization.

The Japanese Employee Suggestion System (ESS) (Basadur, 1992) is one specific example of how an organization's culture, structure and dominant coalition can be deliberately employed to induce creativity. Employees are trained from the first day that research and development (R\&D) is everybody's business. Creative activity is deliberately induced - from the beginning, employees are trained to be "constructively discontented" with one's job and with the company products, and to seek out ways to improve them. Employees are encouraged to publicly post problems that they sense or anticipate, and to interact with their coworkers to solve such problems and demonstrate that their solutions are implementable. Suggestions are submitted and automatically accepted; managers are trained to provide positive feedback and praise for every completed suggestion. Typically, small monetary awards are provided for each implemented suggestion.

It is not uncommon for each employee in ESS companies to devise and implement 60 new suggestions per year. For example, in one company of 9,000 employees, 660,000 employee suggestions were implemented in one year. Of these, 6,000 were new products or product improvements.

When the Japanese managers were asked what the primary objective of their employee suggestion system was, none mentioned new products or new methods, lower costs or higher profits. In fact, none of them mentioned any direct economic outcomes. All of them emphatically said that motivated people was the primary objective. Observable benefits include: motivated employees who want to participate in on-going creative activity; employees who work harder on their routine tasks; decreased absenteeism and tumover (Locke, 1976); increased group 
interaction and teamwork. Economic benefits include increased organizational efficiency and the creation of new methods, goods and services.

Figure 9 models how the variables discussed above relate to one another and how an organization can benefit from increased creativity. When asked how they had learned to concentrate on motivation first, and let economic outcomes fall into place afterwards, the Japanese managers replied, "Why, in your North American textbooks on management".

This example serves to point out that there are deliberate means that organizations can develop to induce creative activity on the job. The Japanese employee suggestion system is merely one way to do so.

\section{Creativity for Job Enrichment}

As shown above, proactive creative activity leads to a continuous flow of new methods and new products. This is called adaptability. Because employees are finding and solving their own problems and implementing the changes themselves, their acceptance of the new solutions is assured because they have high ownership in them. In effect, they are redesigning their own jobs, which is consistent with a well-documented axiom of social psychology: people do not resist change; they do resist being changed (Coch \& French, 1948). Employees enrich their own jobs by being creative. Perhaps this is the missing link for companies who have tried elaborate approaches to job redesign and job enrichment and come up dry.

\section{Superior Teamwork Through Creativity}

Cohen, Whitmeyer and Funk (1960) showed that teams receiving significant training in creative thinking produced superior solutions to real world managerial problems than untrained teams. Basadur, Graen and Scandura (1986) demonstrated that the effects of training in Simplex 


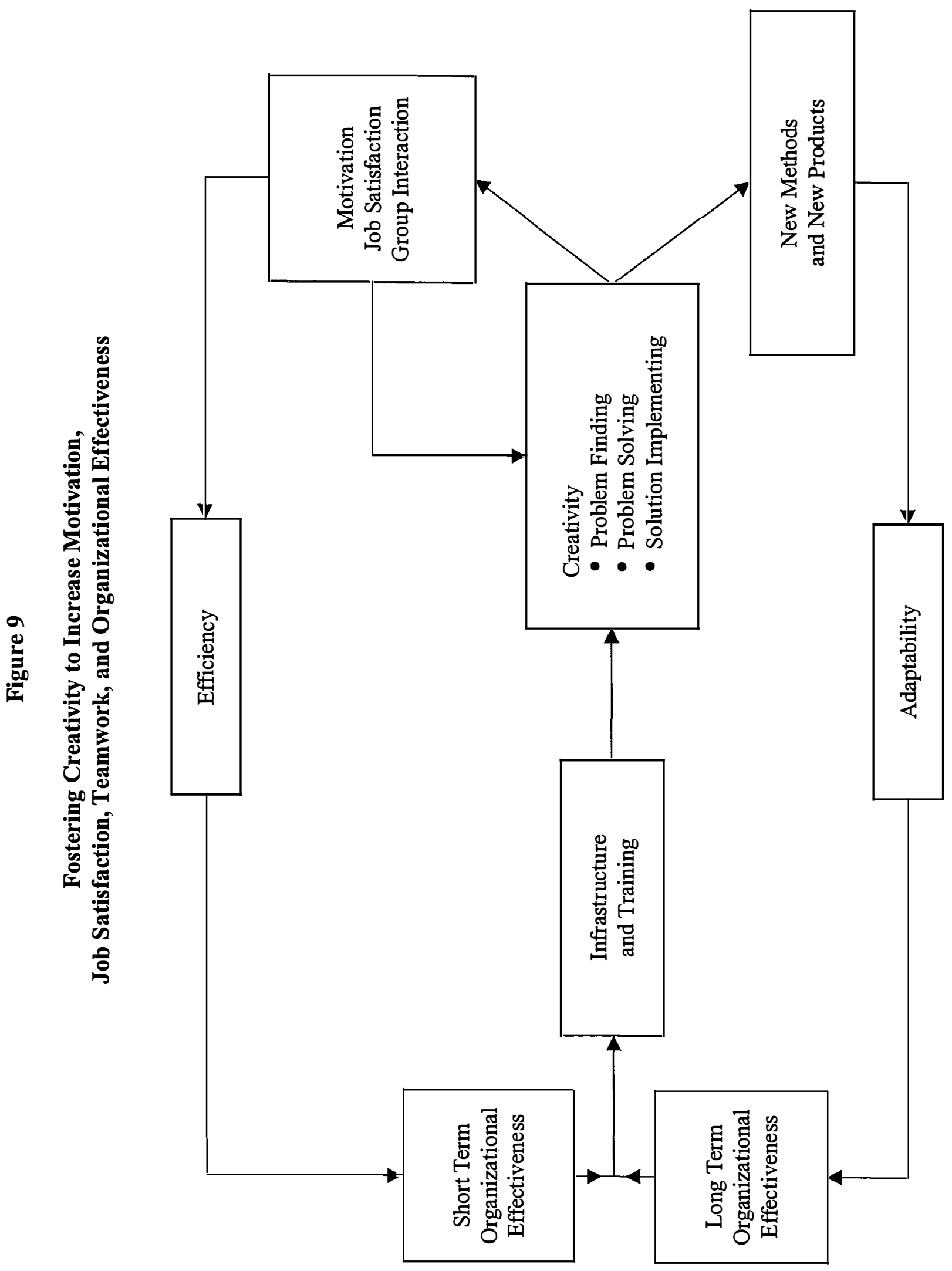


last longer on the job when real, intact teams undergo training together. Teams trained learn to accept and share their members' diverse experience more completely, support differing viewpoints, and risk implementing novel ideas (Basadur, Graen \& Green, 1982). This helps to avoid "group think", the tendency for members to follow the crowd into inadequate solutions instead of offering possibly controversial, superior viewpoints. Applying the Simplex process and process skills makes participation in problem solving safe and fun because people no longer fear advancing fledgling points of view and do not feel they must be constantly on guard.

\section{Building a Better Bargaining Team}

A company's union members and managers wished to avoid the kind of negotiating deadlocks and subsequent strikes that had shut down the plant four times within the previous ten years. They wanted to try a more collaborative approach. Here's how Simplex was employed in union-management contract negotiations to generate imaginative solutions that would have been stifled by the more traditional adversarial bargaining process (Basadur, 1988).

The bargaining process is often a "win-lose" contest, as illustrated in the conflict resolution model in Figure 10 adapted from Thomas (1976). What one side wins, the other automatically loses. When negotiations get really heated and both sides fail to compromise anywhere along the bargaining line, some of the pie is actually thrown away. Moving beyond the bargaining line into the "win-win" area requires creativity.

One contract item was "additional vacation time". Active divergence in fact finding revealed that many people hadn't been taking their full vacation time for fear that their job might be eliminated, or in the belief that they couldn't afford a vacation. Following the Simplex process, the group redefined these challenges into problem statements for which solutions could be found. 


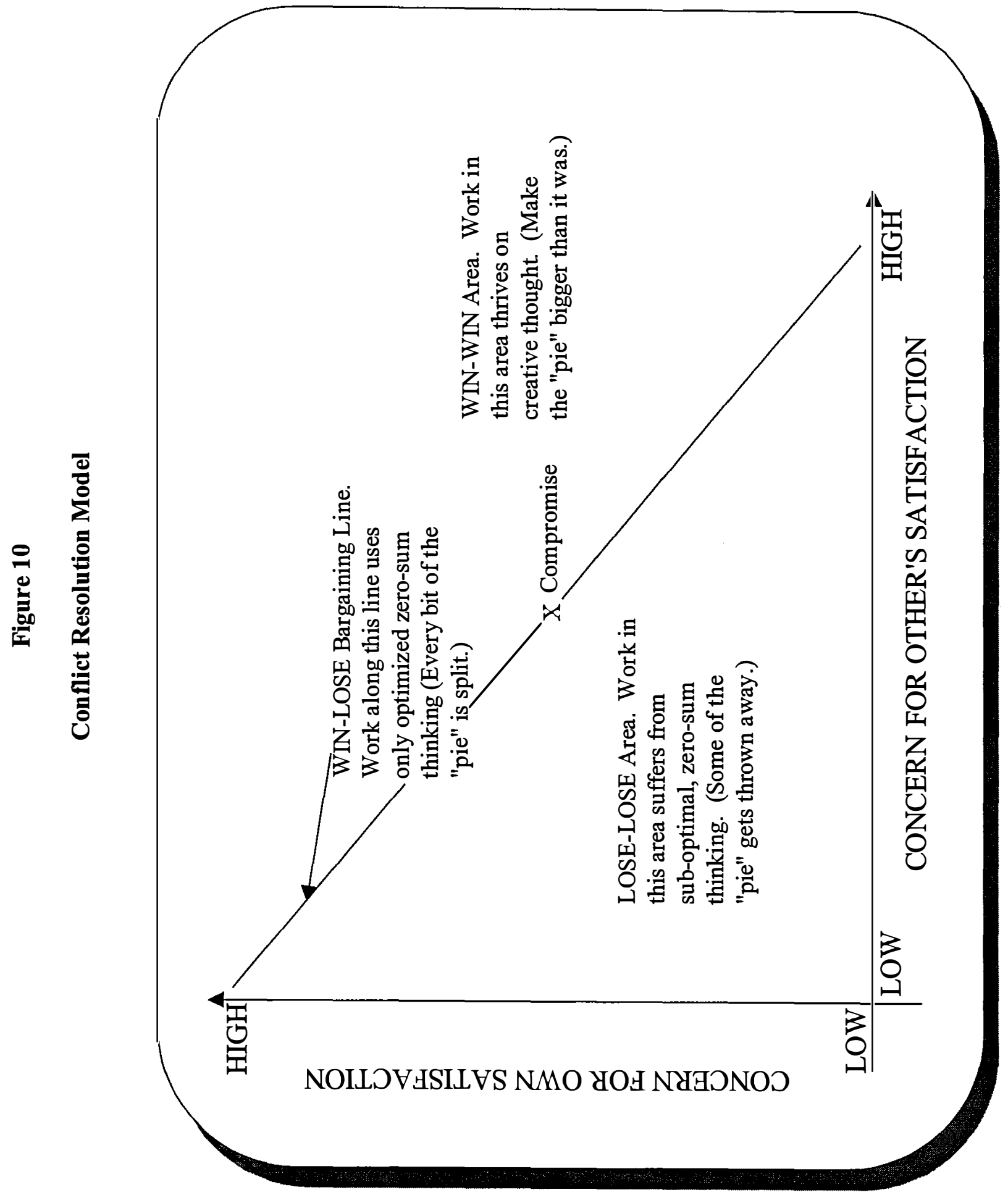


For each contract item in tum, the team alternately diverged and converged to create novel problem definitions, solutions, and action plans to revise the items. Within two months, the group had applied the process to twenty-five contract items, and had developed a more harmonious, cooperative atmosphere. Probably the most important lesson about creativity and teamwork from this example is that creative problem definition allows two groups that believe they have few common objectives - or even feel they have opposing objectives - to find out what they actually have in common.

\section{"We're on the Same Side"}

A second example of creative problem solving and teamwork is provided in Basadur (1994a). Seven top managers and seven top franchise owners of a large consumer goods corporation had been assembled as a team to improve the entire organization's efficiency. For years, relations between the corporate managers and the independent franchisees had been strained by mistrust, conflicting goals and miscommunication. Each side blamed the other for mistakes.

After undergoing training (separately) in the Simplex innovative thinking process, the two groups met for two and one half days along with an expert facilitator. The meeting succeeded, partly because the team members made a real effort to use the four process skills, no matter how painful. But the real key to success was a strategic problem definition map that the group developed after fact finding (Figure 11). The members agreed that their most significant challenge was, "How might we build two-way trust in order to come up with mutually agreed goals?" They felt that solving this problem and implementing the solutions would take them 80 percent of the way toward achieving their overall goal, which they re-defined as, "How might we help each other improve operating profitability?" 
Figure 11

\section{Corporate-Franchisee Top Management Team Problem Definition Map}

Note: $\mathrm{HMW}=$ How might we...?

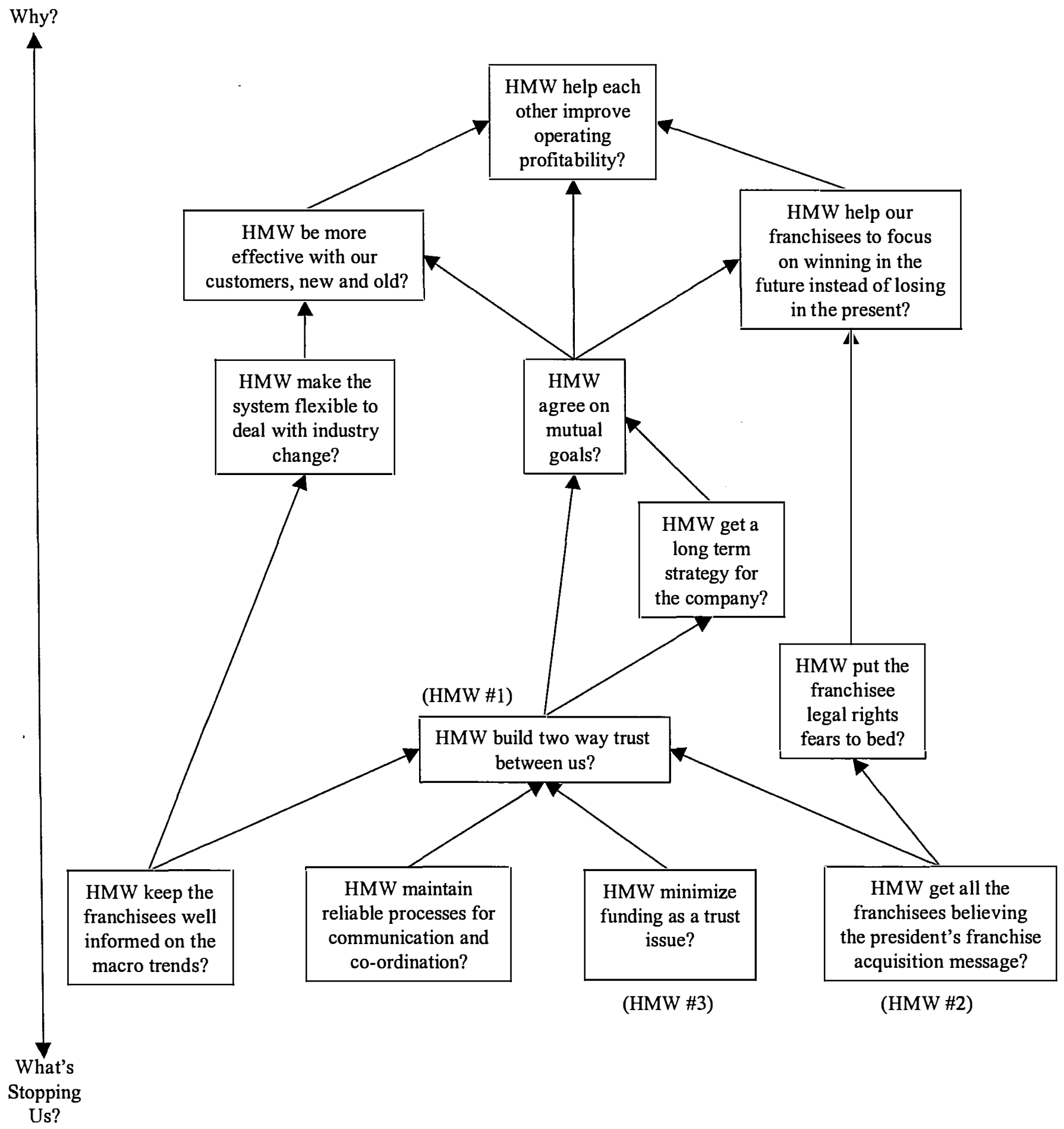




\section{Turnover, Absenteeism and Personal Development}

The link between inducing creativity on the job and increasing job satisfaction and commitment is important not only from the perspective of having happier and more motivated people at work, but in other ways as well. As suggested above, some of these ways are directly economic. Industrial and organizational psychology research has found substantial correlations between job satisfaction and commitment and direct economic variables such as lower turnover and lower absenteeism (Locke \& Latham, 1990; Organ, 1987). Other outcomes which are both people and economically oriented include better selection, placement, career planning, and personal development for organizational members. For example, if we understand peoples' unique individual thinking and creative problem solving process styles better, we can match them with jobs better.

\section{Faster Moving Projects}

The innovative thinking skills of active divergence and convergence, deferral of judgment and vertical deferral of judgement enable projects to be completed more quickly. For example, the Frito-Lay Corporation used the Simplex process to reduce the time to test and implement a new packaging idea from 36 to 9 months (Paton, 1986; Basadur 1984a, b, c, d). Projects move faster, including new ideas for patentable products, cost improvement, meeting test market and national expansion deadlines, and generating new marketing ideas and brand strategies. Thinking is synchronized and the work of different departments is done simultaneously, in parallel, not sequentially. Not only can everyday functional work be done better with the informal use of creative thinking skills, but so can special work on major, targeted problems in formal creative application sessions as described earlier in this chapter. Application opportunities range widely in every function, including product development, marketing, 
personnel, engineering, manufacturing information technology, and purchasing. Applioation opportunities can also include suppliers (Basadur, 1989), and the finance and accounting functions (Basadur, 1998c).

\section{The Creative Process as the Transformationạl Engine}

Increased creativity by applying the Simplex process thus can accelerate the identification and solution of problems and opportunities in every function and department of any organization. These problems and opportunities may originate in both the external and internal environments of the organization, and as they are moved through fact finding, problem definition and then solution optimization and implementation, the organization is operating as a true open system. How the Simplex innovation process acts as the transformational engine for an open social and economic system is modeled in Figure 12.

\section{SUMMARY}

In an era of rapidly accelerating change, thriving organizations are not merely efficient, but also innovative, acting as open systems sensitive to their environments and continuously transforming changing inputs into changing outputs. Organizational creativity or innovation can be modeled as a three-phase, circular transformation process: problem finding, solution development and solution implementation. The four stages of this process, called the Simplex process, are generation, conceptualization, optimization and implementation. Within this process are eight steps: problem finding, fact finding, problem defining, idea finding, evaluating and selecting, planning, gaining acceptance and taking action. Each step is activated by four specific attitudinal and thinking skills called active divergence, active convergence, deferral of judgment, and vertical deferral of judgment. Individuals have unique preferences for various stages of the 
process and these differences can be identified using the CPSP inventory. By deliberately encouraging people to respect individual differences in preferences, and to develop skills in applying the whole process to their work daily, an organization can simultaneously achieve both the economic outputs they crave and also the people outputs they must provide to assure continued economic success in the long run.

Figure 12

\section{How the Simplex Process Permits an Organization} to Operate as a Social and Economic Open System

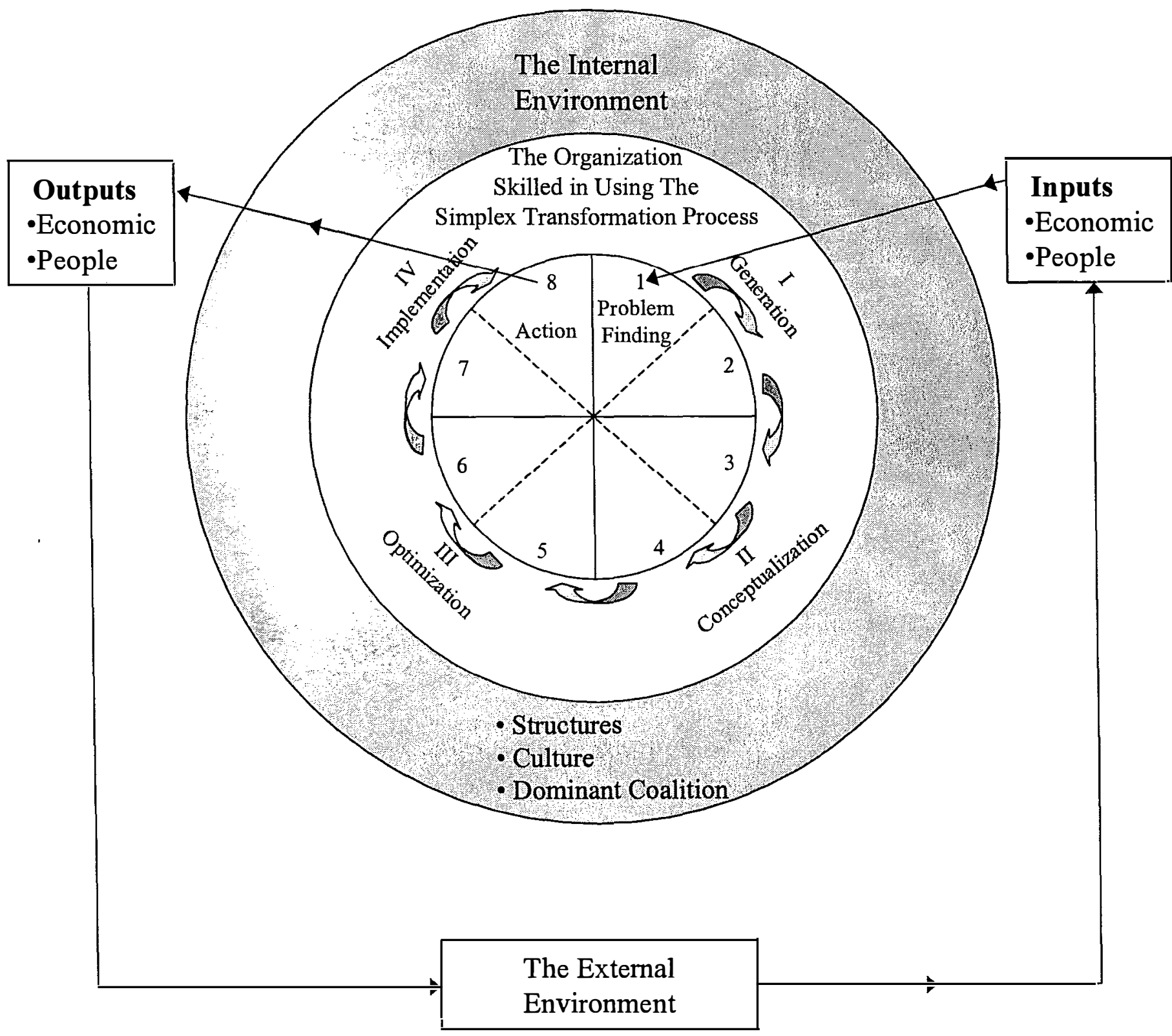


Creativity is an important tool which organizations can use to increase their effectiveness, competitiveness, and long-term survival. To induce the innovative process in an organization is not an easy task. New thinking skills need to be taught and learned, structures must be created to get the new skills into everyday use on the job, and the dominant coalition must lead the way through their own innovative behaviors.

Innovation is not something that can be turned on and off; an organization must make it routine - and managers must lead proactively in making it so.

Increased creativity in organizations provides both economic and people outcomes. Although some of the economic outcomes result directly from creative activity, the majority are valuable by-products of placing priority on achieving people outcomes first. Creativity leads to such direct economic outcomes as a continuous supply of new and improved products and methods for the organization. It also leads to intrinsically motivated, committed, and jobsatisfied people who enjoy getting involved and teaming up with others. These people outcomes are valuable in themselves but more importantly, they lead to the desired economic outcomes.

Improved organizations are eminently possible through creativity, and virtually every kind of organization can benefit. Commitment is needed, however, by senior management to do what it takes to carefully plan, create, and implement an approach to increasing creativity that makes sense uniquely for its organization. This means both a prior identification of the precise results expected and a trust that this effort will succeed. It also requires structural changes to ensure new creative skills will be solidified and nurtured. Creative behavior must become mainstreamed and institutionalized over the long term in order to make the outcomes identified in this chapter permanent realities. 


\section{REFERENCES}

Amabile, T.M. (1993). Motivational synergy: Toward new conceptualization of intrinsic and extrinsic motivation in the workplace. Human Resource Management Review, 3, 185201.

Basadur, M.S. (1998a). The Basadur Simplex creative problem-solving profile inventory: Development, reliability and validity. Management of Innovation and New Technology Research Centre Working Paper No. 83, McMaster University, Hamilton, Ontario, Canada L8S 4M4 (December).

Basadur, M.S. (1998b). Improving the psychometric properties of the Basadur Simplex Creative Problem Solving Profile Inventory. Management of Innovation and New Technology Research Centre Working Paper No. 84, McMaster University, Hamilton, Ontario, Canada L8S 4M4 (December).

Basadur, M.S. (1998c). Discovering the right questions about the management of technology using challenge mapping. Management of Innovation and New Technology Research Centre Working Paper No. 85, McMaster University, Hamilton, Ontario, Canada L8S 4M4 (December).

Basadur, M.S. (1997). Organizational development interventions for enhancing creativity in the work place. Journal of Creative Behavior, 31 (1), 59-72.

Basadur, M.S. (1995a). The power of innovation. London: Pitman Professional Publishing.

Basadur, M.S. (1995b). Optimal ideation-evaluation ratios. Creativity Research Journal, 8 (2), 63-75.

Basadur, M.S. (1994a). Simplex: A flight to creativity. Buffalo, NY: Creative Education Foundation Press. Spanish title: Simplex: un viaje hacia la creatividad.

Basadur, M.S. (1994b). Managing the creative process in organizations. In M.A. Runco (Ed.), Problem finding, problem solving, and creativity. Chapter 12. Norwood, NJ: Ablex.

Basadur, M.S. (1993). Impacts and outcomes of creativity in organizational settings. In S.G. Isaksen, M.C. Murdock, R.L. Firestein, and D.J. Treffinger (Eds.), Nurturing and developing creativity: The emergence of a discipline (pp. 278-313). Norwood, NJ: Ablex.

Basadur, M.S. (1992). Managing creativity: A Japanese model. Academy of Management Executive, 6 (2), 29-42.

Basadur, M.S. (1989). Creative leadership technology. The Cincinnati Purchasor, 68 (1), 11-15.

Basadur, M.S. (1988). Improving union-management bargaining using a special process of applied creative thinking. McMaster University Faculty of Business Research and Working Paper Series, No. 300, Hamilton, Ontario, Canada, L8S 4M4. 
Basadur, M.S. (1984a). Productivity case study: Offsetting costs at Frito-Lay. Productivity, 5 (4), 1-3.

Basadur, M.S. (1984b). Creative problem solving: Uncorking the genie in the bottle. Productivity, 5 (8), 1-4.

Basadur, M.S. (1984c). Creative problem solving: Rounding the turm. Productivity, 5 (9), 4-6.

Basadur, M.S. (1984d). Creative problem solving: Mapping the road to success. Productivity, 5 (10), 4-5.

Basadur, M.S. (1983). Employee involvement creative problem-solving workshop. In Ford Education and Training Catalog, Ford Education and Personnel Research Department, Dearborn, MI, September, (p. 115).

Basadur, M.S. (1982). Research in creative problem solving training in business and industry. Proceedings of Creativity Week 4. Greensboro, NC: Center for Creative Leadership.

Basadur, M.S. (1981). Training in creative problem solving and measuring improvement. Engineering Digest, 27 (3), 59-61, Toronto, Ontario.

Basadur, M.S. (1979). Training in creative problem solving: Effects on deferred judgment and problem finding and solving in an industrial research organization. Doctoral Dissertation, University of Cincinnati, Cincinnati, Ohio, December.

Basadur, M.S. (1974). Think or sink. The Deliberate Methods Change Bulletin, JulySeptember, Procter \& Gamble Management Systems Division, Cincinnati, Ohio.

Basadur, M.S., Ellspermann, S.J., \& Evans, G.W. (1994). A new methodology for formulating ill-structured problems. OMEGA: The International Journal of Management Science, 22, 627-645.

Basadur, M.S. \& Finkbeiner, C.T. (1985). Measuring preference for ideation in creative problem solving training. Journal of Applied Behavioral Science, 21 (1), 37-49.

Basadur, M.S., Graen, G.B., \& Green, S.G. (1982). Training in creative problem solving: Effects on ideation and problem finding in an applied research organization. Organizational Behavior and Human Performance, 30, 41-70.

Basadur, M.S., Graen, G.B., \& Scandura, T.A. (1986). Training effects on attitudes toward divergent thinking among manufacturing engineers. Journal of Applied Psychology, 71 (4), 612-617.

Basadur, M.S., Graen, G.B., \& Wakabayashi, M. (1990). Identifying individual differences in creative problem solving style. Journal of Creative Behavior, 24 (2), 111-137. 
Basadur, M.S. \& Robinson, S.J. (1993). The new creative thinking skills needed for total quality management to become fact not just philosophy. American Behavioral Scientist, 37 (1), 121-138.

Basadur, M.S., Runco, M.A., \& Vega, L.A. (in press). Understanding how creative thinking skills, attitudes and behaviors work together in real world managerial problem solving. Journal of Creative Behavior.

Basadur, M.S. \& Thompson, R. (1986). Usefulness of the ideation principle of extended effort in real world professional and managerial problem solving. Journal of Creative Behavior, 20 (1), 23-34.

Basadur, M.S., Wakabayashi, M., \& Graen, G.B. (1990). Attitudes towards divergent thinking before and after training: Focusing upon the effect of individual problem solving styles. Creativity Research Journal, 3 (1), 22-32.

Beer, M. (1980). Organization change and development: A systems view. Santa Monica, CA: Goodyear.

Berlyne, D.E. (1967). Arousal and reinforcement. In D. Levine (Ed.), Nebraska symposium on motivation. Lincoln, NE: University of Nebraska Press.

Bouchard, T.J. (1972). Training, motivation, and personality as determinants of the effectiveness of brainstorming groups and individuals. Journal of Applied Psychology, 56 (4), 324331.

Bouchard, T.J. \& Hare, M. (1977). Size, performance and potential in brainstorming groups. Journal of Applied Psychology, 54 (1), 51-55.

Campbell, J.P. \& Pritchard, R.D. (1976). Theories of motivation. In M.D. Dunnette (Ed.), The Handbook of Industrial and Organizational Psychology. Chicago, IL: Rand McNally.

Coch, L. \& French, J.R.P., Jr. (1948). Overcoming resistance to change. Human Relations, 1, 512-532.

Cohen, D., Whitmeyer, J.W., \& Funk, W.H. (1960). Effect of group cohesiveness and training upon creative thinking. Journal of Applied Psychology, 44 (5), 319-322.

Coupland, D. (1992). Shampoo planet. New York: Pocket Books.

Deci, E.L. \& Ryan, R.M. (1985). Intrinsic motivation and self-determination in human behavior. New York: Plenum Press.

Dunnette, M.D., Campbell, J., \& Jaastad, K. (1963). The effects of group participation on brainstorming effectiveness for two industrial samples. Journal of Applied Psychology, 47, 30-37. 
Gordon, W.J.J. (1956). Operational approach to creativity. Harvard Business Review, 34 (6), 41-51.

Hackman, J.R. \& Oldham, G.R. (1980). Work re-design. Reading, MA: Addison-Wesley.

Herzberg, F.L. (1966). Work and the nature man. Cleveland: World Publishing.

Herzberg, F., Mausner, B., \& Snyderman, B. (1959). The motivation to work (2 ${ }^{\text {nd }}$ ed.). New York: Wiley.

Kirton, M.J. (1987). KAI Manual. Hertsford, U.K.: Hatfield Occupational Research Centre.

Kotter, J.P. (1978). Organization dynamics: Diagnosis and Intervention. Reading, Mass.: Addison-Wesley.

Kraut, A.I. (1976). Developing managerial skills via modeling techniques: Some positive research findings - a symposium. Personnel Psychology, 29, 325-328.

Lakein, A. (1973). How to get control of your time and your life. New York: Peter H. Wyden, Inc.

Locke, E.A. (1976). Nature and causes of job satisfaction. In M.D. Dunnette (Ed.), Handbook of Industrial and Organizational Psychology, Chapter 30. Chicago, IL: Rand-McNally.

Locke, E.A. \& Latham, G.P. (1990). Work motivation and satisfaction: Light at the end of the tunnel. Psychological Science, 1 (4), 240-246.

Maltz, M. (1961). Psycho-Cybernetics. New York: Pocketbooks.

Margulies, N. \& Raia, A.P. (1978). Conceptual foundations of organizational development. New York: McGraw-Hill.

Maslow, A.H. (1954). Motivation and personality. New York: Harper and Row.

McClelland, D.C. (1961). The achieving society. Princeton, NJ: Van Nostrand.

McClelland, D.C. (1951). Personality. New York: Dryden Press.

Miles, R.E. \& Snow, C. (1978). Organization strategy, structure, and process. New York: McGraw-Hill.

Morgan, G. (1993). Imagination: The art of creative management. California: Sage Publications Inc.

Mott, P.E. (1972). The characteristics of effective organizations. New York: Harper \& Row.

Neher, A. (1991). Maslow's Theory of Motivation: A Critique. Journal of Humanistic Psychology, 31 (3), 89-112. 
Organ, D.W. (1987). Organizational citizenship behavior: The good soldier syndrome. Lexington, MA: Lexington.

Osborn, A.F. (1963). Applied imagination. NYC: Scribners.

Parnes, S.J. (1961). Effects of extended effort in creative problem solving. Journal of Educational Psychology, 52 (3), 117-122.

Parnes, S.J. \& Meadow, A. (1959). Effects of "brainstorming instructions on creative problem solving by trained and untrained subjects.' Journal of Educational Psychology, 50 (4), 171-176.

Parnes, S.J., Noller R.B., \& Biondi, A.M. (1977). Guide to creative action. New York: Charles Scribner's Sons.

Paton, B.R. (1986). Competitive edge through creativity: Frito-Lay's success story of the ' 80 's. Unpublished doctoral dissertation, Columbia Pacific University.

Runco, M.A. and Basadur, M.S. (1993). Assessing ideational and evaluative skills and creative styles and attitudes. Creativity and Innovation Management, 2 (3), 166-173.

Shaw, M.E. (1971). Group dynamics: The psychology of small group behavior. New York: McGraw-Hill.

Simon, H.A. (1977). The new science of management decisions. Englewood Cliffs, NJ: Prentice-Hall.

Taylor, F.W. (1967). Principles of scientific management. New York: W.W. Norton.

Taylor, D.W., Berry, P.C., \& Block, C.H. (1958). Does group participation when using brainstorming facilitate or inhibit creative thinking? Administrative Science Quarterly, 3, 23-47.

Thomas, K. (1976). Conflict and conflict management. In M.D. Dunnette (Ed.), The Handbook of Industrial and Organizational Psychology. Chicago, IL: Rand McNally.

Tice, D.M. \& Baumeister, R.F. (1997). Longitudinal study of procrastination, performance, stress and health: The costs and benefits of dawdling. Psychological Science, 8 (6), 454458.

Toffler, A. (1970). Future shock. New York: Random House.

White, R.W. (1959). Motivation reconsidered: The concept of competence. Psychological Review, 66 (5), 297-333. 


\section{MANAGEMENT OF INNOVATION AND NEW TECHNOLOGY WORKING PAPER SERIES}

1. R.G. Cooper and E.J. Kleinschmidt, "How the New Product Impacts on Success and Failure in the Chemical Industry", February, 1992.

2. R.G.Cooper and E.J. Kleinschmidt, "Major New Products: What Distinguishes the Winners in the Chemical Industry", February, 1992.

3. J. Miltenburg, "On the Equivalence of JIT and MRP as Technologies for Reducing Wastes in Manufacturing, March, 1992.

4. J.B. Kim, I. Krinsky and J. Lee, "Valuation of Initial Public Offerings: Evidence from Korea", February, 1992.

5. M. Basadur and S. Robinson, "The New Creative Thinking Skills Needed for Total Quality Management to Become Fact, Not Just Philosophy", April, 1992.

6. S. Edgett and S. Parkinson, "The Development of New Services Distinguishing Between Success and Failure", April, 1992.

7. A.R. Montazemi and K.M. Gupta, "Planning and Development of Information Systems Towards Strategic Advantage of a Firm", April, 1992.

8. A.R. Montazemi, "Reducing the Complexity of MIS Innovation Through Hypermedia and Expert Systems", May, 1992.

9. M. Basadur and Bruce Paton, "Creativity Boosts Profits in Recessionary Times - Broadening the Playing Field", June, 1992.

10. Robert G. Cooper and Elko Kleinschmidt, "Stage-Gate Systems for Product Innovation: Rationale and Results", June, 1992.

11. S.A.W. Drew, "The Strategic Management of Innovation in the Financial Services Industry: An Empirical Study", July, 1992.

12. M. Shehata and M.E. Ibrahim, "The Impact of Tax Policies on Firms' R \& D Spending Behavior: The Case of R \& D Tax Credit", July, 1992. 
13. Willi H. Wiesner, "Development Interview Technology: Implications for Innovative Organizations", July, 1992.

14. Isik U. Zeytinoglu, "Technological Innovation and the Creation of a New Type of Employment: Telework", August, 1992.

15. John W. Medcof, "An Integrated Model for Teaching the Management of Innovation in the Introduction to Organizational Behaviour Course", October, 1992.

16. Min Basadur, "The Why-What's Stopping Analysis: A New Methodology for Formulating Ill-Structured Problems", October, 1992.

17. Stephen A.W. Drew, "Strategy, Innovation and Organizational Learning an Integrative Framework, Case Histories and Directions for Research", November, 1992.

18. Stephen A.W. Drew, "Innovation and Strategy in Financial Services", November, 1992.

19. Scott Edgett, "New Product Development Practices for Retail Financial Services", November, 1992.

20. Robert G. Cooper and Elko J. Kleinschmidt, "New Product Winners and Losers: The Relative Importance of Success Factors - Perception vs. Reality", November, 1992.

21. Robert G. Cooper and Elko J. Kleinschmidt, "A New Product Success Factors Model: An Empirical Validation", November, 1992.

22. Robert G. Cooper \& Elko J. Kleinschmidt, "Stage Gate Systems: A Game Plan for New Product Success", November, 1992.

23. Min Basadur, "Optimal Ideation-Evaluation Ratios", March, 1993.

24. Christopher K. Bart, "Gagging on Chaos", March, 1993.

25. Yufei Yuan, "The Role of Information Technology in Business Innovation", July, 1993.

26. Isik Urla Zeytinoglu, "InnovationinEmployment: A Telework Experiment in Ontario", July, 1993.

27. John Miltenburg and David Sparling, "Managing and Reducing Total Cycle Time: Models and Analysis", August, 1993.

28. R.G. Cooper, C.J. Easingwood, S. Edgett, E.J. Kleinschmidt and C. Storey, "What Distinguishes the Top Performers in Financial Services", September, 1993.

29. B.E. Lynn, "Innovation and Accounting Research", September, 1993. 
30. Min Basadur and Peter Hausdorf, "Measuring Additional Divergent Thinking Attitudes Related to Creative Problem Solving and Innovation Management", November, 1993.

31. R.G. Cooper and E.J. Kleinschmidt, "Determinants of Time Efficiency in Product Development", December, 1993.

32. Christopher K. Bart, "Back to the Future: Timeless Lessons for Organizational Success", February, 1994.

33. Ken R. Deal and Scott J. Edgett, "Determining Success Criteria for New Financial Products; A Comparative Analysis of CART, Logit and Discriminant Analysis", February, 1995.

34. Christopher K. Bart and Mark C. Baetz, "Does Mission Matter?", February, 1995.

35. Christopher K. Bart, "Controlling New Products: A Contingency Approach", February, 1995.

36. Christopher K. Bart, "Is Fortune Magazine Right? An Investigation into the Application of Deutschman's 16 High-Tech Management Practices", February, 1995.

37. Christopher K. Bart, "The Impact of Mission on Firm Innovativeness", February, 1995.

38. John W. Medcof, "Transnational Technology Networks", April, 1995.

39. R.G. Cooper and E.J. Kleinschmidt, "Benchmarking the Critical Success Factors of Firms' New Product Development Programs", April, 1995.

40. John W. Medcof, "Trends in Selected High Technology Industries", July, 1995.

41. Robert C. Cooper \& E.J. Kleinschmidt, "Benchmarking Firms' New Product Performance \& Practices", September, 1995.

42. Min Basadur and Darryl Kirkland, "Training Effects on the Divergent Thinking Attitudes of South American Managers", November, 1995.

43. Min Basadur, "Organizational Development Interventions for Enhancing Creativity in the Workplace", November, 1995.

44. Min Basadur, "Training Managerial Evaluative and Ideational Skills in Creative Problem Solving: A Causal Model", December, 1995. 
45. Min Basadur, Pam Pringle and Simon Taggar, "Improving the Reliability of Three New Scales Which Measure Three New Divergent Thinking Attitudes Related to Organizational Creativity", December, 1995.

46. N. P. Archer and F. Ghasemzadeh, "Project Portfolio Selection Techniques: A Review and a Suggested Integrated Approach", February, 1996.

47. Elko J. Kleinschmidt, "Successful new product development in Australia: An empirical analysis", February, 1996.

48. Christopher K. Bart, "Industrial Firms \& the Power of Mission," April, 1996.

49. N. P. Archer and F. Ghasemzadeh, "Project Portfolio Selection Management through Decision Support: A System Prototype," April, 1996.

50. John W. Medcof, "Challenges in Collaboration Management in Overseas Technology Units," April, 1996.

51. Susan L. Kichuk and Willi H. Wiesner, "Personality and Team Performance: Implications for Selecting Successful Product Design Teams," May, 1996.

52. Susan L. Kichuk and Willi H. Wiesner, "Selection Measures for a Team Environment: The Relationships among the Wonderlic Personnel Test, The Neo-FFI, and the Teamwork KSA Test, "May, 1996.

53. Susan L. Kichuk and WilliH. Wiesner, "Personality, Performance, Satisfaction, and Potential Longevity in Product Design Teams," June, 1996.

54. John W. Medcof, "Learning, Positioning and Alliance Partner Selection," June, 1996.

55. Scott J. Edgett, "The New Product Development Process for Commercial Financial Services," July, 1996.

56. Christopher K. Bart, "Sex, Lies \& Mission Statements," September, 1996.

57. Stuart Mestelman and Mohamed Shehata, "The Impact of Research and Development Subsidies on the Employment of Research and Development Inputs," November, 1996.

58. Mark C. Baetz and Christopher K. Bart, "Developing Mission Statements Which Work," November, 1996.

59. Fereidoun Ghasemzadeh, Norm Archer and Paul Iyogun, "A Zero-One Model for Project Portfolio Selection and Scheduling," December, 1996. 
60. R. G. Cooper, S. J. Edgett, E. J. Kleinschmidt, "Portfolio Management in New Product Development: Lessons from Leading Firms," February 1997.

61. R. G. Cooper, S. J. Edgett, E. J. Kleinschmidt, "Portfolio Management in New Product Development: Lessons from Leading Firms -- Part II," February 1997.

62. C. K. Bart, "A Comparison of Mission Statements \& Their Rationales in Innovative and Non-Innovative Firms," February 1997.

63. R. Bassett, N. P. Archer and W. G. Truscott, "Data Webs: An Evaluation of an Innovative Information Management Tool that Integrates Databases with the World Wide Web," April 1997.

64. S. Taggar, "Intelligence, Personality, Creativity and Behaviour: The Antecedents of Superior Team Performance," April 1997.

65. R. Deaves and I. Krinsky, "New Tools for Investment Decision-Making: Real Options Analysis," May 1997.

66. J. W. Medcof (ed.), "Trends and Events in Selected High Technology Industries," May, 1997. (On the WEB only)

67. C. K. Bart, "Product Innovation Charters: A State-of-the-Art Review," May, 1997.

68. John W. Medcof, "Strategic Contingencies and Power in Networks of Internationally Dispersed R\&D Facilities", August, 1997.

69. John W. Medcof, "Research Intensity and the Identification of High Technology Industries," September, 1997.

70. Christopher K. Bart and John C. Tabone, "Mission Statements in the Not-for-profit Health Care Sector: A State of the Art Review," September, 1997.

71. Elko J. Kleinschmidt, "In-house and Partnership New Product Development in Austria: An Empirical Analysis on Outcome and Explanatory Factors," October, 1997.

72. Robert G. Cooper, Scott J. Edgett and Elko J. Kleinschmidt, "R\&D Portfolio Management Best Practices: Methods Used \& Performance Results Achieved," January, 1998.

73. Christopher K. Bart and Simon Taggar, "A Model of the Impact of Mission Rationale, Content, Process and Alignment on Firm Performance," March, 1998.

74. Christopher K. Bart, John Parkinson and Simon Taggar, "The Implementation of Strategy: Behavioural vs Budgetary Approaches and the Effect of Participation,” March, 1998. 
75. John W. Medcof, "The Resource Based View and the New Competitive Landscape: Characterizing Positions of Dynamic Capability," May, 1998.

76. F. Ghasemzadeh and N. P. Archer, "Project Portfolio Selection Through Decision Support," June, 1998.

77. Y. Yuan, N. Archer, and R. Bassett, "The Impact of Electronic Commerce Innovations on Marketing Management," June, 1998.

78. Kenneth S. Chan, James Chowhan, Stuart Mestelman, Mohamed Shehata, "Value Orientations and Income and Displacement Effects," July 1998.

79. Min Basadur, Laurent Lapierre, "Predicting Creative Problem Solving Behaviors within Teams," September, 1998.

80. Min Basadur, "Simplex: Modelling the Phases and Stages of the Innovation Process in OpenSystem Organizations", October, 1998.

81. Ken Deal, Ben Long and Bryan Scott, "New Pricing Product Design for Competitive Advantage", November, 1998.

82. Min Basadur, Mark A. Runco and Luis A. Vega, "Understanding How Creative Thinking Skills, Attitudes and Behaviors Work Together in Real World Managerial Problem Solving," November, 1998.

83. Min Basadur, "The Basadur Simplex Creative Problem-Solving Profile Inventory: Development, Reliability and Validity", December, 1998.

84. Min Basadur, "Improving the Psychometric Properties of the Basadur Simplex Creative Problem Solving Profile Inventory,” December, 1998.

85. Min Basadur, "Discovering the Right Questions about the Management of Technology Using Challenge Mapping," December, 1998.

86. Nick Bontis, "Managing an Organizational Learning System by Aligning Stocks and Flows of Knowledge: An Empirical Examination of Intellectual Capital, Knowledge Management, and Business Performance," January, 1999.

87. Nick Bontis and John Girardi, "Teaching Knowledge Management and Intellectual Capital Lessons: An Empirical Examination of the Tango Simulation," January, 1999.

88. Karen Boehnke, Nick Bontis, Joseph J. DiStefano and Andrea C. DiStefano, "Transformational Leadership: An Examination of Cross-Cultural Differences and Similarities," January, 1999. 
89. John W. Medcof, "The Resource Based View and Transnational Technology Strategy," May 1999.

90. Harish C. Jain and Parbudyal Singh, "Innovative Recruitment and Selection Strategies for Visible Minority Police Officers in Selected Canadian Police Organizations," June 1999.

91. Laurent M. Lapierrê, "The Measurement of Transformational Leadership Revisited: Confirming, the MLQ factor Structure in Autonomous Work Teams, October 1999.

92. Naresh C. Agarwal and Parbudyal Singh, "Organizational Change, Innovation and Reward Systems: A Look at Theory and Practice," December 1999.

93. Nick Bontis and Jason Mill, "Web-Based Metrics and Internet Stock Prices," January 2000.

94. Nick Bontis and Honsan Chung, "Software Pricing Structures in Electronic Commerce: 3 Different Cases," January 2000.

95. John W. Medcof, "Resource Based Strategy and Managerial Power in Networks of Internationally Dispersed Technology Units," January 2000.

96. John W. Medcof, “Dynamic Capabilities: A Neo-Contingency Theory?”, January 2000.

97. John W. Medcof, "On the Road to the New Business Paradigm: How Far is too Far?", January 2000.

98. Michael H. Mitchell and Nick Bontis, “A CKO's Raison D’etre: Driving Value-Based Performance Gains by Aligning Human Capital with Business Strategy," January 2000.

99. Min Basadur, "Evaluating the Psychometric Improvements Provided by Basadur CPSP 2Experimental," September 2000. 
Innis REF HD 45 . W657 no. 100 
The activities of the Management of Innovation and New Technology Research Centre are generously supported by:

- The DeGroote family

- DuPont Canada Inc

- Nórtel

- Royal Bank

- The Society of Management Accountants of Ontario

\section{McMaster University MICHAEL G. DEGROOTE SCHOOL OF BUSINESS}

\section{INFORMATION ...}

For information about the Management of Innovation and New Technology Research Centre or innovation research activities at the Michael G. DeGroote School of Business:

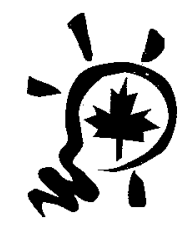

Director; Dr. C. K. Bart, Ph.D., C.A. MINT - Research Centre Michael G. DeGroote School of Business McMaster University, 1280 Main St. W. Hamilton ON Canada L8S 4M4

Phone: 905-525-9140, Ext. 24105

Fax: $905-521-8995$

email: mint@mcmaster.ca www: http://mint.mcmaster.ca/

${ }^{*}$ Management of Innovation and New Technology Research Centre (MINT) is an official mark of the Michael G. DeGroote School of Business, McMaster University. 